\title{
Geographically-resolved social cost of anthropogenic emissions accounting for both direct and climate-mediated effects
}

\author{
Jennifer Burney ${ }^{1 *}$, Geeta Persad ${ }^{2 *}$, Jonathan Proctor ${ }^{3}$, Eran Bendavid ${ }^{4}$, \\ Marshall Burke ${ }^{5}$, Sam Heft-Neal ${ }^{6}$
}

${ }^{1}$ School of Global Policy and Strategy, University of California, San Diego, USA (jburney@ucsd.edu; @jaburney)

2 Department of Geological Sciences, University of Texas at Austin, USA (Geeta.Persad@jsg.utexas.edu; @ggpersad)

3 Center for the Environment and Data Science Initiative, Harvard University, USA (jproctor91@gmail.com)

${ }^{4}$ Department of Medicine, Stanford University, USA (ebd@stanford.edu)

5 Department of Earth System Science, Stanford University, USA (mburke@stanford.edu; @MarshallBBurke)

${ }^{6}$ Center on Food Security and the Environment, Stanford University, USA (sheftneal@stanford.edu; @samheftneal)

*Equal Contributions, Communicating Authors: jburney@ucsd.edu, Geeta.Persad@jsg.utexas.edu

We welcome your feedback on this research; feel free to contact the authors via email. We note that this is a non-peer-reviewed pre-print. We have submitted the manuscript for peerreview at Nature Sustainability. Subsequent versions of this manuscript may include revisions based on feedback and the peer-review process. If accepted at Nature Sustainability or elsewhere, the final version of this manuscript will be available via the "Peer-reviewed Publication DOI" link on the EarthArXiv page for this paper. 


\title{
Geographically-resolved social cost of anthropogenic emissions accounting for both direct and climate-mediated effects
}

\author{
Jennifer Burney $^{1 *}$, Geeta Persad $^{2 *}$, Jonathan Proctor $^{3}$, Eran Bendavid ${ }^{4}$, Marshall Burke $^{5}$, Sam \\ Heft-Neal $^{6}$
}

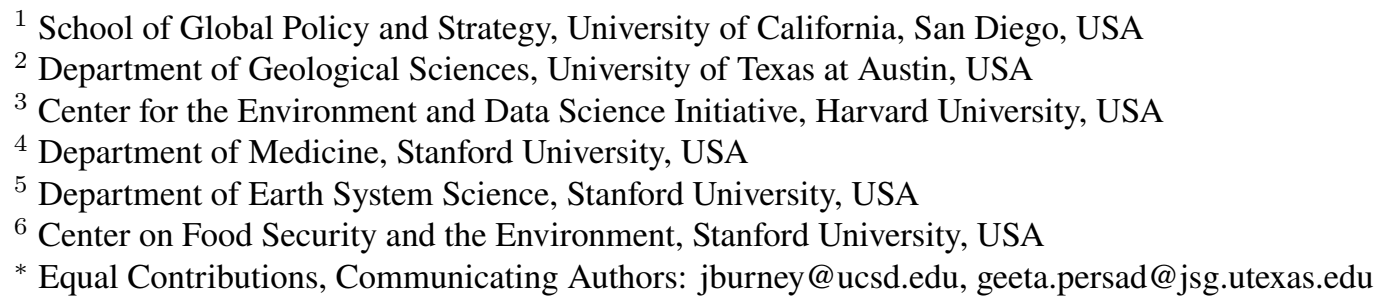

The magnitude and distribution of physical and societal impacts from long-lived greenhouse gases are insensitive to the emission source location; the same is not true for major co-emitted short-lived pollutants like aerosols. Here we combine novel global climate model simulations with established response functions to show that identical aerosols emitted from different regions (Brazil, China, East Africa, Western Europe, India, Indonesia, USA, and South Africa) produce divergent air quality and climate changes and associated human system impacts, both locally and globally. The marginal global damages to infant mortality, crop productivity, and economic growth from aerosol emissions and their climate effects differ by more than an order of magnitude depending on source region, with certain regions-particularly developed regions in the northern mid-latitudes—creating global external climate changes and impacts much larger than those felt locally. Importantly, these aerosol impacts arise from region-specific aerosol-climate interactions, are magnified by the geography and vulnerability of underlying human systems, and drastically increase both local and remote benefits to reducing emissions from human activity, particularly in the emerging economies assessed. These findings provide quantitative evidence that a social cost calculation incorporating geographically-resolved climate and air quality impacts from both long- and short-lived emissions would both increase incentives for mitigation and strongly differentiate between source regions, potentially stimulating coordination between regions with interlinked damages.

Credible climate accounting - or the valuation of impacts from anthropogenic emissions - requires linking emissions from known sources to their downstream benefits and damages. A robust literature has emerged to estimate the social cost of carbon (SCC), or the marginal damages associated with an additional emission of carbon dioxide $\left(\mathrm{CO}_{2}\right) .{ }^{1-5}$ Development of the SCC methodology has benefited from the physical reality that $\mathrm{CO}_{2}$ is long-lived and well-mixed in the atmosphere, and its impacts on the earth system are thus independent of emission location. Along with $\mathrm{CO}_{2}$, 
however, human activities also produce co-emissions of shorter-lived compounds - including black and organic carbon aerosols, carbon monoxide, nitrogen oxides, volatile organic compounds, sulfur dioxide, and other trace chemicals - that are not well-mixed and thus likely exert geographically heterogeneous influence on atmospheric composition, climate, and human systems. ${ }^{6-8}$ A full cost-benefit analysis of any mitigation action or policy would ideally take into account the emission location and balance the cost of mitigation against the full suite of benefits that would accrue from all mitigated co-emissions, in addition to $\mathrm{CO}_{2}$.

Although the idea of accounting for such co-benefits is not new, ${ }^{9-12}$ geographically-resolved climate accounting has yet to be implemented, because it requires tracing both the air quality and climate impacts of identical emissions from different locations. Previous studies have either focused only on air quality-related health impacts, ${ }^{13-15}$ assessed emissions from a single region, ${ }^{16-18}$ used simplified models without coupled chemistry and climate, ${ }^{15,19-24}$ or have modeled emissions reduction scenarios where emissions are simultaneously reduced across broad areas, which cannot isolate the full impact of an emission from a particular location. ${ }^{25-28}$ Building on recent literature on the spatial dependence of aerosol-climate interactions, ${ }^{7,29-33}$ here we link novel aerosol perturbation experiments in a fully dynamical, global chemistry-climate model with empirically-estimated damage functions to map the size and spatial distribution of physical changes and societal damages that accrue when identical aerosols are emitted from eight representative regions (Brazil, China, East Africa, Western Europe, India, Indonesia, USA, South Africa; Figure S1). In doing so, we comprehensively quantify the geographically-resolved societal impacts of aerosol emissions, not only through their localized effects on air quality (i.e. surface concentrations of $\mathrm{PM}_{2.5}$ and column-integrated Aerosol Optical Depth) but also through their heterogeneous impacts on climate (i.e. temperature and precipitation). To our knowledge, this is the first study to geographically resolve the per-emission impacts of aerosols from different regions in a fully integrated climate modeling framework that simultaneously considers air quality and climate pathways. Many important outcomes are known to be multivariate functions of environmental exposures. By utilizing a fullycoupled chemistry-climate model, our methodology allows us to assess, in a self-consistent manner, impacts due to changes across a range of environmental parameters that are all affected in spatially- and temporally- varying ways by the aerosols and their precursors that are co-emitted with $\mathrm{CO}_{2}$.

The analysis framework is shown in Figure S1. In brief, we run the NCAR CAM5 model coupled to a slab ocean for 100 years with a repeating annual cycle of boundary conditions. In the control environment, global $\mathrm{CO}_{2}$ concentrations are held at year 2000 levels and aerosols are fixed at 1850 levels. In the perturbation environment, we separately impose an additional aerosol emissions burden generated in one of the 8 regions (experimental conditions). The additional emissions burden is equal in magnitude and composition across experiments and includes a modern representative mix (roughly equivalent to year 2000 emissions in China) of Black Carbon (BC), Organic Carbon $(\mathrm{OC})$, and Sulfate precursor $\left(\mathrm{SO}_{2}\right)$, which is interactively transported, aged, and removed by the circulation and 
chemistry of the model. While other co-emitted pollutants - including heavy metals, high-GWP gases, and ozone precursors like NOx, methane, and other volatile organic compounds - are known to contribute to secondary aerosol formation and to impact human health, plant health, and climates, $\mathrm{BC}, \mathrm{OC}$, and $\mathrm{SO}_{2}$ drive the vast majority of nonGHG climate effects ${ }^{34}$ and are the main anthropogenic contributors to present-day $\mathrm{PM}_{2.5}$ levels in most regions. ${ }^{35,36}$

We then link the steady-state environmental changes in each experiment to established exposure-response functions from the literature to estimate impacts on infant mortality (due to surface $\mathrm{PM}_{2.5}$ concentrations), ${ }^{37}$ yields of main staple crops (due to changes in temperature, precipitation, and Aerosol Optical Depth (AOD); AOD is a measure of aerosol abundance in the full thickness of the atmosphere and influences the quantity and quality of light available for photosynthesis), ${ }^{38}$ and macroeconomic growth (which shows a strong, non-linear response to temperature). ${ }^{39}$ While aerosols likely impact other important outcomes, both directly (e.g., adult morbidity and mortality) and indirectly (e.g., changes in soil moisture that lead to increased fire risk), we examine these three outcomes because they are key determinants of welfare and occur on annual or shorter time-scales, and are thus separable from longer run aerosol(or GHG-) mediated processes. By holding the total quantity and composition of the emissions portfolio constant, but varying its source location against an otherwise fixed-aerosol background, we test the extent to which a set of annual impacts of this mix of $\mathrm{BC}+\mathrm{OC}+\mathrm{SO}_{2}$ vary based on source location. To then scale these physically-equivalent emissions scenarios to regionally-representative conditions, we normalize to per-unit impacts, and then normalize to regional $\mathrm{CO}_{2}$ emissions to produce realistic co-emissions impacts (see Methods for details). Critically, we consider co-benefits and co-damages that occur not just from air quality impacts, but also from geographically-resolved aerosol-induced climate changes.

\section{Results}

We find a large divergence in impacts resulting from identical amounts of aerosols emitted from each source region that begins with strongly differing physical system responses in both air quality and climate conditions. After emission, primary $\mathrm{BC}$ and $\mathrm{OC}$ aerosols, and secondary sulfate aerosols formed from $\mathrm{SO}_{2}$, are wafted into the atmosphere, transported, and deposited through a suite of mechanisms. Although the physical distribution of the particulates at the surface remains mostly local to the region of origin (Figure 1A), higher up in the atmosphere aerosols are transported farther, resulting in increased aerosol optical depth locally and in downwind regions (Figure 1B). These aerosols then exert radiative effects on climate by absorbing and scattering incoming radiation both directly and indirectly through cloud nucleation ( $\mathrm{se}^{8}$ for additional discussion). This changes the temperature structure of the surface and atmospheric column, which in turn affects larger-scale circulation patterns (Figure 1C). Finally, aerosols affect precipitation via changes to atmospheric stability and large-scale circulation and, potentially, through interactions 
with clouds as condensation nuclei (Figure 1D).

Global-mean increases in surface $\mathrm{PM}_{2.5}$ and column AOD from each region's emissions both vary by a factor of 2.5 (Figure 1A-B, Figure S2A, and Table S1), symptomatic of differences in the removal processes and atmospheric transport patterns present in the ambient environment into which the aerosols are emitted. ${ }^{40,41}$ Global-mean temperature effects vary by more than an order of magnitude (Figure 1C). Broadly, the distribution of the aerosols, the strength of regional radiative forcings produced, and the efficacy of the forcing at producing climate feedbacks all contribute to the magnified temperature differential relative to the surface $\mathrm{PM}_{2.5}$ and column AOD differential. ${ }^{8}$ Global-mean total precipitation reductions vary by a factor of more than 6 (Figure 1D), but are strongly correlated $(r=0.95)$ with the global-mean temperature response (Figure S2B), and can be viewed as a global hydrologic cycle response to the aerosol-induced cooling. ${ }^{42}$ The diversity of responses to identical emissions demonstrates that the geographic distribution of sources is a critical determinant of aerosols' influence on the physical environment.

These aerosol-driven changes to both air quality and climate conditions would be expected to affect a range of societal outcomes. Here we evaluate three major welfare impacts - infant mortality, staple crop production, and gross domestic product (GDP) - that have been shown in studies of the recent past to respond to atmospheric changes on annual (or shorter) time scales. $\mathrm{PM}_{2.5}$ in the surface air layer exposes infants both in-utero and during infancy, which can increase the risk of respiratory infections, ${ }^{43}$ low birth weight ${ }^{44}$ and neonatal mortality ${ }^{45}$ (Table S2). The net impact of AOD on photosynthetically available light (increasing diffuse but decreasing direct sunlight at the surface) reduces yields of maize, soy, rice, and wheat ${ }^{38}$ while cooling and reduced precipitation during the growing season due to aerosols can either increase or decrease productivity depending on crop type and on baseline growing conditions relative to the optimum (Table S3). ${ }^{46}$ At a macroeconomic level, annual GDP growth has been shown to have a non-linear response to temperature (Table S4). ${ }^{39}$ We quantify "global" (i.e. aggregated over the entire globe), "external" (i.e. aggregated only outside the aerosol source region), and "local" (i.e. aggregated only within the aerosol source region) impacts, such that global impacts are the sum of local and external impacts.

We find that the divergence in aerosol physical impacts is further magnified by the co-location of impacted social systems and their underlying vulnerabilities. That is, the more spatial overlap between physical system changes and human systems, and the more vulnerable the human system, the larger the social impact. The geographic distributions of crop areas and human populations are shown in Figure S3A; their vulnerability is characterized by baseline conditions (infant mortality rate, baseline crop yields, baseline per capita GDP), shown in Figure S3B. The influence of co-location of physical and human systems is summarized in Figure S4, which shows how simple land area average, population-weighted average, and crop area-weighted average changes in $\mathrm{PM}_{2.5}$, AOD, Temperature, and Precipitation can differ by up to a factor of 2 (e.g., local area average versus crop-weighted average precipitation for 
Indonesia, global average versus population-weighted infant mortality for Europe).

The confluence of physical impact heterogeneity and the geography of human systems and vulnerabilities means that global infant mortality impacts span almost two orders of magnitude across scenarios (Figures 2A,B and S5A)-a range ten-fold larger than the variation in surface $\mathrm{PM}_{2.5}$ changes. Aggregate crop productivity effects range from strongly negative to weakly positive (Figures 2C and S5B), as does GDP change (Figures 2D and S5C), even though all source regions produce the same global-mean sign of change in the associated physical system drivers (temperature, precipitation, and AOD in the case of crop productivity and temperature in the case of economic growth). Results are summarized in Tables S5 and S6.

The degree of co-location of increased surface pollution with large vulnerable infant populations is the leading driver of disparities in excess infant deaths from the different source regions, as well as the degree to which impacts are felt locally versus globally (Figures 2B, S5A, and S4). The Indian and East African emissions scenarios, which produce the most excess infant deaths, do so primarily via the co-location of the resulting surface pollution with large and highly vulnerable infant populations (Figure S3). The lower number of excess deaths from the U.S. emissions scenario emerges partially because the distribution of surface pollution produced is biased away from populated areas and infant numbers and because vulnerability is relatively low in the populated areas affected.

Indian emissions produce the largest total atmospheric aerosol loadings ${ }^{8}$ and therefore largest increase in $\mathrm{PM}_{2.5}$; this is strongly confined to the source region, likely due to the partial geographic barrier to ventilation created by the Himalayas. The spatial pattern of $\mathrm{PM}_{2.5}$ increase is highly co-located with large, vulnerable infant populations as well, compounding with the large $\mathrm{PM}_{2.5}$ increase to generate large infant mortality effects. European emissions do not produce as large of a total increase in $\mathrm{PM}_{2.5}$, but the increase is spatially dispersed and co-located with external regions that have large, vulnerable infant populations. Combined with low infant vulnerability within Europe, this produces the strongly externalized impacts (four times as many excess infant deaths outside regional boundaries compared to inside).

The spatial distribution of crop productivity stems from the distributions of the four crop types assessed (Figure S3 as well as their relative sensitivity to each of the three driving physical system changes (AOD, temperature, and precipitation) (Table S3). In cases where crop productivity effects are of a different sign outside vs. inside the source region (e.g. Europe and South Africa), the local AOD-driven reduction of photosynthetically available light dominates the crop response and generates large local crop productivity declines (Figures 2C, S5B, S4, and S6). In areas external to the source region, temperature and precipitation effects dominate the influence on crop productivity and may have either positive or negative impacts depending on the optimality of the baseline climate in that region for a 
given crop type. Wheat is the largest driver of overall productivity declines (Figure S6), amplified by the co-location of patterns of strong physical system change with wheat-growing regions in most of the experiment configurations.

Indian emissions again produce the largest negative global total crop impacts, but the global totals are largely driven by strong within-India (i.e. local) impacts. The same mechanisms that produce the large local surface $\mathrm{PM}_{2.5}$ concentrations in response to Indian emissions contribute to enhanced local AOD loading, which drives large absolute declines in the local production rate of all crop types, particularly wheat and rice (Figure S6). India has extensive area devoted to these crops, including some very high-yielding regions. Emissions from Europe and South Africa damage local crop productivity while benefiting aggregate external crop productivity (Figure $2 \mathrm{C}$ and S5B). In these cases, aggregate external crop productivity is enhanced by the large-scale cooling generated by aerosols from these regions (Figure S6), which is more geographically dispersed than the increased AOD (Figure 1). However, it should be noted that emission source locations with aggregate local crop benefits still cause discernable declines throughout northern Africa, the Middle East, and South Asia (Figure S5B).

The geographic distribution of macroeconomic effects (Figure 2D and S5C) bears the fingerprint of the dependence of the underlying economic damage function on baseline climatological conditions in the impacted region. ${ }^{39} \mathrm{Be}-$ cause the aerosols cool globally regardless of source location, regions whose climatological temperature is above the economic optimum (e.g. India) experience cooling-driven economic benefits from their own emissions, while those with climatological temperature below or at the economic optimum (e.g. China, U.S.) experience cooling-driven economic damages. An exception to this is Europe, driven by the fact that the large temperature changes induced by European emissions occur primarily outside of the source region. No source region generates net global aggregate damages, though all emissions regions have important distal impacts (Figure S5C).

We explore the relative contributions of the physical changes, the geography of human systems, and their underlying vulnerability by comparing our simulations to constructed scenarios in which either (a) the physical system changes are spatially homogeneous (held at the global mean change for each scenario); (b) the spatial distributions of the impacted system (infants, crops, and people) are homogeneous; or (c) the spatial distribution of vulnerability is homogeneous (i.e., constant mortality rates, crop yields, and baseline GDP). The global results are shown in Figure S7 (and Figure S8 for individual crop details). For both infant mortality and crop production, the physical distribution of aerosols is the main driver of the total impact, at both the global and country level (insets). For GDP, the impacts are driven more heterogeneously by different physical impacts, the quadratic damage function, and the distribution of people (and therefore economic activity). For all three outcomes, underlying vulnerability plays a relatively small role. 
The diversity and spatial heterogeneity of these computed economic, human health, and agricultural damages suggest that including such effects in an aggregate social cost of anthropogenic activity would introduce new geographic structure to mitigation cost-benefit analyses. To contextualize this, we normalize the constant aerosol emissions used in our perturbation experiments to co-emitted $\mathrm{CO}_{2}$ emissions to map our experimental conditions onto more realistic scenarios. We normalize using both global-average (Table S7) and region-specific (Table S8) BC:CO ${ }_{2}, \mathrm{OC}_{\mathrm{CO}} \mathrm{CO}_{2}$, and $\mathrm{SO}_{4}: \mathrm{CO}_{2}$ ratios drawn from spatially explicit inventories ${ }^{47}$ to show how the local emissions portfolio changes this calculation. We use regional average values as representative of the regional average ratio (and thus impact or cost), even though this ratio varies widely within regions both across space and across sectors (Figure S15). These normalized impacts provide a direct estimate of how aerosols modify the damages associated with marginal carbon dioxide emissions, or the Social Cost of Carbon (Figure 3). We monetize impacts using average crop prices ${ }^{48}$ and standard methods for estimating the value associated with premature mortality (Value of Statistical Life, or VSL; see Methods). ${ }^{49-51}$ We show impacts per $\mathrm{tCO}_{2}$ both in physical and monetary units to facilitate both multi-attribute and single-dimensional benefit-cost analysis; when aggregating impacts across sectors, we sum mortality and GDP impacts, but not agricultural production, since agricultural production is recorded within GDP (Methods). We find that, on a per tonne of $\mathrm{CO}_{2}$ basis, the co-emissions of aerosols add $\$ 4$ to $\$ 139$ to the value of the $\mathrm{CO}_{2}$-only Global Social Cost of Carbon (GSCC, $\$ 418 / \mathrm{tCO}_{2}$ ). These numbers grow under other assumptions about the VSL (Figure 3), in some cases exceeding the GSCC. The aerosol-based modification to the GSCC is highest for Indian emissions, reflecting mortality impacts that are not offset by global total increased economic output. The modification is lowest in percentage terms for Brazil (\$4.44) and Indonesia (\$5.65), although the values for Europe and the United States are lower if a global average VSL is used. These smaller regional impacts are due to either smaller effects in both domains (e.g., the United States) or offsetting effects (Brazil). Figure 3 shows the total impacts across GDP and mortality pathways; the corresponding Table S8 shows that, across all emitting regions, these totals are dominated by the excess mortality costs.

Interestingly, when compared to the damages from $\mathrm{CO}_{2}$ that accrue at the national level (i.e., the Country-level Social Cost of Carbon, or $\mathrm{CSCC}^{4}$ ), taking into account the effects of the localized aerosol impacts dramatically alters the cost-benefit calculus for many emitting regions (Figure 3, red crosses). It more than doubles the value for China, and raises it from negative to positive for Europe. India's value rises by 40\%, South Africa's by a factor of 10 (from $\$ 3.3$ for $\mathrm{CO}_{2}$ alone to $\$ 32$ when localized aerosol effects are included), and Eastern Africa's value grows from less than one dollar due to $\mathrm{CO}_{2}$-related damages to over $\$ 30$ when aerosol effects are included. These values are even higher when the local composition of emissions is taken into account. Areas with high coal and diesel emissions (China and India) have higher ratios of aerosols to $\mathrm{CO}_{2}$ emissions and therefore a much greater fraction of social costs due to aerosol-related damages. Finally, while emissions from all locations generate total global GDP benefits 
via cooling, we find that this is not driven by net benefits in agriculture, which we consider to be included in the total GDP benefit estimate (Figure S16). For example, most GDP gains from Indian emissions are generated locally, but crop losses total to around a tenth of that amount.

\section{Discussion and Conclusions}

Although warming from anthropogenic $\mathrm{CO}_{2}$ generation creates heterogeneous impacts around the world, these $\mathrm{CO}_{2}$ specific damages are independent of emission location. The key conclusion of this analysis is that the dynamics of aerosol damages are entirely different. Their short-term local and global impacts are strongly dependent on the location of emission, and heterogeneity in those impacts is strongly driven by the physical interactions between aerosols and the general circulation, not simply the distribution of impacted human systems or their underlying vulnerabilities. Therefore, because aerosols are co-emitted with $\mathrm{CO}_{2}$, accounting for them in the social cost of emissions fundamentally changes the mitigation paradigm. The analysis presented here builds on previous work to characterize these different types of anthropogenic emissions, ${ }^{10,20,52,53}$ and extends and formalizes these ideas by creating an experimental framework and methodology to more fully assess the full impact of a diverse emissions portfolio in a physically consistent manner. The importance of our full-system approach simultaneously considering both air quality and climate pathways is illustrated in Figure S10, which shows how estimates vary when crop impacts are assessed using only AOD versus AOD, temperature, and precipitation.

By assessing the impacts of identical emissions from multiple major source regions, we are able to identify the geographic distribution of marginal damages and, consequently, of mitigation incentives for each source region, enabling mapping of cooperation incentives and optimal mitigation investments. Importantly, inclusion of impacts of co-emitted aerosols and their precursors changes both the global and localized costs associated with anthropogenic emissions. For the 8 emitting regions, inclusion of these effects should raise marginal willingness to pay for mitigation of emissions in global and purely self-serving ("localized") terms. Perhaps surprisingly, even when using non-linear damage functions that have the potential for positive impacts (benefits) to aerosol emissions, we find that 'local' impacts are always negative. This is a critical note, since simultaneous mitigation of SLCPs and $\mathrm{CO}_{2}$ would be expected to amplify local warming in the short-run by removing the aerosol-driven cooling (e.g. Figure 1) that currently masks a portion of longer-run greenhouse gas-driven warming.

At the regional scale, these analyses suggest that inclusion of co-emitted aerosol impacts may change the nature of cooperation incentives as well. It has been noted that Arctic nations would benefit from formation of mitigation 'clubs' outside the international climate change framework. ${ }^{54}$ When we aggregate our estimated impacts from the 
8 test regions, and consider each as both sources of emissions and receptors of impacts (Figure S9), we see that receptor regions' interests lie disproportionately across sub-groups of source regions, and thus that the potential for mitigation 'clubs' also arises here. Regionally, the regional pairs of Eastern Africa and India, and India and China, share strong connections for infant mortality and crop impacts that might incentivize additional mitigation, even for these emerging economies. Europe, the United States, and China exert strong temperature driven GDP impacts around the world that meaningfully change the financial value of mitigation for each region, whether considering global or localized impacts. Although these $8 \times 8$ matrices are only a subset of source/receptor relationships, this framework provides a roadmap for the type of analyses that should eventually underlie valuation of the full suite of emissions from human activity, and how their downstream effects are 'traded'. Impacts of each source region globally, on specific receptor regions, and locally are different for each type of societal impact. An understanding of a full suite of impacts and relationships would thus allow each country to proceed with mitigation decisions according to their own valuations of damages and partnerships across the globe.

This analysis has several limitations that suggest that specific impact numbers should be interpreted cautiously. We start from a framework of identical emissions from each source region to appropriately disentangle the effect of the physical earth system - how it processes and disperses aerosols from different locations - from the underlying heterogeneous distributions of populations and land uses at the earth's surface. Although we subsequently normalize results to make them more easily translatable to present conditions, this analysis underscores the importance for future observationally-constrained emissions inventories to both probe potential shortcomings of the linearities assumed here and to more finely capture regional variations in emissions (this is especially important in biomass-dependent economies where inventories are known to be much less accurate). ${ }^{55-57}$ The potential attractiveness of $\mathrm{CO}_{2}+$ aerosol mitigation would also be expected to change if new technologies (e.g., diesel truck filters) altered the ratio of aerosol to $\mathrm{CO}_{2}$ emissions. This further underscores the importance of spatially-, temporally-, and sectorally- resolved multispecies inventories to anchor benefit-cost analyses of all human activities that generate emissions.

Finally, our analyses here include only a small subset of aerosol-related impact pathways, selected because they involve responses that occur over shorter (and, therefore, separable) time scales, have large welfare implications, and for which response functions are well-established. However, aerosols are expected to exhibit impacts through other pathways - for example, $\mathrm{PM}_{2.5}$ has been shown to have impacts on adult morbidity and mortality, cognitive performance, and productivity; ${ }^{43,58,59}$ aerosol-driven radiation effects would be expected to impact forests and native habitats in addition to crops; ${ }^{60-62}$ and changes in temperature and precipitation have been linked to other important social impacts besides economic output ${ }^{63,64}$ - that are not included here. In addition, other co-emitted pollutants including heavy metals, high-GWP gases, and especially ozone precursors like NOx, methane, and other volatile organic compounds - are known to impact human health, plant health, and climates. NOx itself is a main precursor to 
nitrate aerosols, and the ability of future models to more fully include nitrogen and other secondary organic aerosol dynamics into this framework will be critical. Future empirical work estimating heterogeneous climate and social effects of regional aerosol emissions, such as those from volcanic eruptions or fires, could provide valuable evaluation of our findings. This analysis thus represents a starting point for consideration of the full suite of human emissions and their impact pathways.

\section{Methods}

\section{Climate model perturbation experiments}

This study uses nine 100-year, repeating annual cycle simulations conducted in the National Center for Atmospheric Research Community Atmosphere Model 5 (NCAR CAM5), run with the modal aerosol module with three lognormal modes (MAM3) and coupled to a mixed-layer ocean. Full details on the simulation set-up may be found in Persad and Caldeira. ${ }^{8}$

We conduct a control simulation using year 2000 climate conditions, including year 2000 atmospheric concentrations of carbon dioxide (367 parts per million) and other greenhouse gases, with non-biomass burning anthropogenic aerosols (black carbon, sulfate precursor, and organic carbon) fixed at 1850 values. We then conduct 8 regional perturbation experiments in which a total annual emission of 22.4 Tg sulfate precursor, $1.61 \mathrm{Tg}$ black carbon, and 4.03 Tg of organic carbon emissions-equivalent to China's year 2000 emissions in CAM5's baseline emissions inventory $^{65}$-is added to one of the 8 source regions, defined according to the Intergovernmental Panel on Climate Change's regional definitions. We opt to focus on this suite of short-lived pollutants due to their dominant role in both climate and air quality impacts. We exclude secondary pollutants, such as tropospheric ozone and nitrate-based secondary aerosol, for which computationally prohibitive interactive gas phase chemistry would be required and for which geographic source apportionment is not straightforward. This fixed emissions burden is distributed within the given source region according to that region's year 2000 values (i.e. according with the realistic within-region distribution of emissions sources), scaled equally at each grid point and time step to produce the desired total addition. Within-region emissions distributions are shown in Figure S14. The difference between each regional perturbation simulation and the control simulation thereby captures the climate response to the addition of an identical total annual aerosol emission located in a given region.

The eight regions are selected to sample a range of past, present, and projected future major source regions of aerosol 
emissions. Europe and the United States dominated non-biomass burning aerosol emissions through the second half of the 20th century; China and India are currently the largest source regions of aerosol emissions; and Indonesia, East Africa, South Africa, and Brazil are all regions where aerosol emissions are projected to grow substantially over the early 21st century across the Representative Concentration Pathway and Shared Socioeconomic Pathway scenarios. ${ }^{65-67}$ The selection of regions, which are located in a range of climatological environments, also allows us to test the sensitivity of the responses to dominant atmospheric and climate processes present in the Northern and Southern Hemisphere mid-latitudes, tropical regions, monsoonal regimes, and upwind and downwind of the major ocean basins.

Our experiment design is motivated by the fact that social cost calculations, emissions accounting, and many regulatory limits use the mass of pollutant emitted as the relevant unit and that comparability across emitting regions is of great interest in international policy discussions. We, therefore, choose to equalize emissions amount across the regions in our simulations rather than (e.g.) atmospheric concentration or emission intensity, which are less straightforwardly translatable for these policy contexts. This could potentially introduce effects due to the differing spatial extents of the regions over which the emissions are imposed, primarily by amplifying air quality impacts in regions with a smaller spatial extent (i.e. where the emissions are more concentrated). To some extent, this reflects actual increased risks from emissions in confined regions where industrial activity is necessarily spatially concentrated and likely to be co-located with population centers (in all cases emissions are distributed within-country according to year 2000 realistic emissions distributions). However, smaller regions do not systematically exhibit stronger air quality effects or associated societal impacts in our results (e.g. Figure 2), suggesting that this effect does not dominate.

Certain aspects of aerosols' climate effects can also be sensitive to the background aerosol concentrations onto which the additional perturbation is added. In particular, there is evidence that adding aerosol to a relatively pristine atmosphere results in (in some cases, two times) larger marginal radiative and cloud effects than adding aerosol to a relatively dirty atmosphere, ${ }^{68,69}$ but confidence in this effect is low. ${ }^{70,71}$ Constructing equal emissions perturbation experiments such as ours will necessarily require making certain decisions about the background climate onto which emissions are added. The aerosol background onto which we add our equal emissions perturbation is not pristine (year 2000 biomass burning aerosols and natural background dust and sea salt aerosols are present in both the control and perturbation experiments), nor is it as polluted as the present-day atmosphere (other anthropogenic aerosol are set at 1850 levels in the control). As such, the marginal physical system effects calculated from our simulations could be viewed as a slight overestimate of the effects of future marginal changes in aerosol emissions, if background atmospheric aerosols increase, or as a slight underestimate, if they decline—-both of which are contemplated in future emissions scenarios. ${ }^{72}$ 
Our use of a fully coupled chemistry-climate model allows us to assess combined climate and air quality impacts of aerosols from the different regions in a fully consistent and physically integrated way. Given that many societal damage functions indicate that societal outcomes respond nonlinearly to combined climate and air quality pressures (represented most clearly in this study in crop yields ${ }^{38}$ ), the simultaneous, internally consistent simulation of these effects that our methodology provides is particularly valuable. The CAM5 model with MAM3 has been shown to produce atmospheric burdens of sulfate, organic carbon and black carbon that align strongly (difference $<10 \%$ ) with atmospheric models containing more complex atmospheric chemistry. ${ }^{73}$ The same holds for radiative forcing from historical aerosol emissions. ${ }^{74}$ When run with historical emissions, the model captures observed geographic and temporal patterns of aerosols concentrations. It produces low-biased AOD, particularly over East and South Asia, but this may be partially the result of uncertainties in historical emissions inventories, which our equal-emissions simulations will not be subject to. ${ }^{73}$ The fully coupled CESM model has demonstrated skill in simulating historical temperature and precipitation at both the global and regional scale, consistently performing among the top 10 or top half of Fifth Coupled Model Intercomparison Project (CMIP5) models for a range of climate metrics. ${ }^{75}$

The model simulations are constructed as equilibrium or "time-slice" simulations to allow quantification of the response to the imposed aerosol perturbation with a robust signal to noise ratio (see e.g. ${ }^{76,77}$ ). Output from the model is monthly, nominal 2-degree (144x96) grids, in netcdf format. The first 40 years of the time-slice simulations are excluded to allow the model to stabilize from initial conditions (determined by when trends in sea surface temperature and top-of-atmosphere energy imbalance become negligible), and analysis is conducted on the last 60 years (720 months) of data as the steady-state response. Each year can be treated as an "ensemble member" (so parameters for this period are calculated for $n=60$ ), due to the primarily sub-annual effects of aerosols and minimal autocorrelation between years. From experiment and control condition runs, we extract the following variables: surface BC, OC, and Sulfate mixing ratios, surface temperature, surface pressure, precipitation, and column AOD. We add surface BC, $\mathrm{OC}$, and $\mathrm{SO}_{4}$ and convert to concentration using local temperature and pressure. For each variable, we then calculate mean changes between each source region and the control condition (e.g., Figure 1), and we aggregate over both the source region and the globe to compare local versus global changes (e.g., Figure S4).

\section{Damage functions and their application}

From perturbation experiments we calculate spatially-explicit changes in four summary physical responses $\Delta P M_{c s}$, $\Delta A O D_{c s}, \Delta T_{c s}$, and $\Delta P_{c s}$ where for each, $c$ is the receptor cell and $s$ is the source region where the aerosols were emitted. Values are aggregated to either annual average changes (infant mortality and GDP) or crop-growing-season averages (corn, wheat, rice, soybean) in each physical parameter, relative to the control runs. 
To connect these physical changes to human-related damages, we then use existing empirically-estimated damage functions that relate changes in these parameters to changes in infant mortality, changes in production from major crops, and changes in economic output. We utilized published damage functions from studies that use panel data (repeated observations of many locations over time) and fixed effects regression models to isolate variation in the exposure of interest (e.g. temperature or PM) from other time-invariant and time-varying factors that could be correlated with both this exposure and the outcome of interest. We note that such damage functions capture adaptations to short-run changes in physical states, such as a farmer irrigating in response to a series of hot days, though they do not capture long-run adaptations, such as a farmer installing irrigation in response to a warmer climate; thus long-run adaptation may cause realized outcomes to differ from simulated responses.

Changes in infant mortality To understand impacts on human life, we relate $\Delta P M_{c s}$ to changes in infant mortality. Impacts are calculated based on the exposure-response function in Heft-Neal et. al. $2018,{ }^{37}$ who in a study of nearly a million African births find that the infant mortality rate increases linearly with $\mathrm{PM}_{2.5}$ exposures, with a $0.9 \%$ increase in infant mortality per $1 \mu \mathrm{gm}^{-3}$ increase in $\mathrm{PM}_{2.5}$ (Table $\mathrm{S} 2$ ). While this response was estimated in the African context, other work has suggested strong similarity in the relative response of IMR to $\mathrm{PM}_{P} 2.5$ across both the developed and developing world from studies that use similar quasi-experimental methodologies. ${ }^{78-80}$ That is, while the total number of infant deaths that occur as a result of a unit increase in PM exposure declines substantially at lower baseline IMR, the proportional impact - i.e. the percent increase in IMR per unit increase in PM - is, if anything, empirically smaller in lower-income higher-mortality regions (Figure S11), perhaps because other there are more competing risks for infant death in lower-income regions. Thus assuming a constant proportional increase based on the African estimate is likely a lower bound on the proportional increase in much of the rest of the world. Total additional excess infant deaths in each receptor country are then calculated as

$$
\Delta I M_{c s}=\Delta P M_{c s} * \beta^{I M R} * I M R_{c} * I_{c}
$$

where $\triangle P M_{c s}$ is the change in infant-population-weighted surface particulate matter, $\beta^{I M R}=0.009$ is the percentage increase in IMR per unit increase in particulate matter (see Table S2), $I M R_{c}$ is the baseline infant mortality rate in each country, ${ }^{81}$ and $I_{c}$ is the estimated infant population in each country ${ }^{82}$ (we approximate the under-1 population as $1 / 5$ of the under-5 population provided in $\left.{ }^{82}\right) . \Delta I M_{c s}$ then gives total excess infant mortality in each country $c$ in a single average year due to emissions in source region $s$, relative to a no-aerosol scenario.

Parameter uncertainty in infant deaths for each scenario is calculated based on the standard errors of the empirical estimate in Heft-Neal et al. $2018^{37}$ (Table S2); uncertainty due to internal climate variability is calculated from vari- 
ation in $\triangle P M_{2.5}$ across the 60 ensemble members. While many estimates of this impact coefficient $\left(\beta^{I M R}\right)$ exist in the literature, we use the Heft-Neal et al. coefficient because it draws on nearly a million births that spans one of our test regions (Eastern Africa, for which there are no other estimates), and is not statistically different from estimates drawn from other study regions (e.g., United States, Europe, China).

Changes in crop production To calculate changes in crop production, we use estimates from Proctor et. al. $2018,{ }^{38}$ who used variations in AOD created by large volcanic eruptions to estimate the impacts of aerosol-driven radiation changes on crop yields, while also accounting for changes in temperature and precipitation also driven by the atmospheric aerosol burden. We calculate change in total production of each of four main staple crops (maize, wheat, rice, soybean) as:

$$
\Delta P R O D_{j c s}=\left[\Delta Y_{j c s} * Y_{j c}\right] * A_{j c}
$$

where $Y_{j c}$ is the baseline yield of each crop $j$ in country $c$ and $A_{j c}$ is the baseline area, where for both we use the estimated 2000 area and yields from ref. ${ }^{83}$ The percentage change in yield $\Delta Y_{j c s}$ is calculated by applying $\triangle A O D_{c s}$, $\Delta T_{c s}$, and $\Delta P_{c s}$ to the response functions estimated in Proctor et. al. $2018,{ }^{38}$ and is done as follows:

$$
\Delta Y_{j c s}=\Delta f\left(A O D_{j c s}\right)+\Delta f\left(T_{j c s}\right)+\Delta f\left(P_{j c s}\right)
$$

where we apply model coefficients to changes in temperature, precipitation, and AOD (Table S3) over crop-specific growing seasons ${ }^{84}$ and areas in each country to calculate national-level yield changes. Specifically, we calculate changes in yield at the pixel-growing season resolution and then average over space (cropped-area weighted average of pixels within a country) and time (60 years) to get a single estimate of $\Delta Y_{j c s}$ for each crop, country and source region. Uncertainty in the crop response from imperfectly estimated empirical model parameters is calculated as in Proctor et. al. 2018. ${ }^{38}$ Uncertainty in the crop response from imperfectly estimated changes in the climate variables is calculated, for each crop, country and source region as the standard error of $Y_{j c s t}$ over years, $t$.

Changes in economic output To calculate changes in macroeconomic output, we use response functions from Burke et. al. 2015, ${ }^{39}$ who find that per capita national economic growth varies strongly and non-linearly with annual average temperature. We calculate the change in total economic output in each country $c$ due to the change in temperature from aerosols from source region $s$ as:

$$
\Delta G D P_{c s}=\left[f\left(T_{c}+\Delta T_{c s}\right)-f\left(T_{c}\right)\right] * G D P p c_{c} * p o p_{c}
$$


where $G D P p c_{c}$ and $p_{p} p_{c}$ are the baseline (2010) per capita GDP and population in country $c$ and $f()$ is the function from Burke et. $\mathrm{al}^{39}$ that estimates the percentage change in per capita GDP in a given year from a change in temperature: $f()=\beta_{1} T_{c t}+\beta_{2} T_{c t}^{2}$, where $T_{c t}$ is the annually averaged temperature in country $c$ in year $t$. Coefficients and standard errors for $\beta_{1}$ and $\beta_{1}$ are given in Table S4. $\Delta G D P_{c s}$ then gives the total change in GDP in country $c$ over one year due to aerosol emissions from source region $s$.

As for infant mortality and crop production, we estimate standard errors based on the statistical model parameter uncertainty, and due to the internal variability of the climate system (e.g., error bars shown in Figure S4).

We note that, in addition to spatial co-location of physical changes and human systems, the temporal dimension also affects calculations of societal damages based on these damage functions. Crops are sensitive to environmental changes within their location-specific growing season. Figure S12 shows the local climatology (from control scenario) for each source region, and then deviations from climatology in that location created by emissions from each source region. For example, Europe's local temperature impacts are strongly concentrated in the summer growing months whereas South Africa's are year-round; Eastern Africa's precipitation effects affect the second rainy season, whereas Indonesia's are year-round. Similarly, although we calculate average annual effects on infant mortality, given that we find strong seasonal variation in $\mathrm{PM}_{2.5}$ concentrations driven by transport and deposition mode timing, we would expect that the variation in total $\mathrm{PM}_{2.5}$ burden, as well as individual $\mathrm{BC}, \mathrm{OC}$ and sulfate burdens (Figure S13) would vary at sub-annual scales. Better understanding of the fidelity of the seasonal behavior of both physical models and damage functions will thus be an important component of improving damage estimates going forward.

\section{Partitioning Aerosol Impacts}

A key question is the extent to which aerosol impacts on human systems are driven by changes in the physical system versus the distribution of underlying human systems and/or their baseline vulnerabilities. To assess this, we compare the results from our main experiments with impacts estimated from three counterfactual scenarios:

- Globally homogeneous physical changes: In this scenario, we use the global-mean change in all parameters induced by aerosols instead of the locally-resolved changes.

- Globally homogeneous distribution of human systems: In this scenario, we spread human systems (infant populations, crop area, human populations) equally over all land areas.

- Globally homogeneous vulnerability: In this scenario, we assume all human systems (infant mortality, crop yields, per-capita GDP) are held at the global average as opposed to their local values. 
We estimate impacts from each emissions region for these three additional scenarios for each of the three impact pathways, and compare results in Figures S7 and S8.

At the global level (Figure S7, left panels), we find that the physical system changes (i.e., the geographic heterogeneity of aerosol interactions with the general circulation from different regions) is the main contributor to both excess infant mortality and crop production changes (the green bars, or the estimates of impacts from a counterfactual homogenous physical system response, are most different from the actual experimental conditions, shown by the grey bars). For economic impacts, the combination of physical system impacts and underlying population distributions (the generators of economic activity) both exert strong influences, but across scenarios the physical impacts are consistently major drivers, while population distribution importance varies across emission regions.

To more concretely understand the relative importance of these factors, we conduct a simple analysis at the country level from the above simulations (Figure S7, right panels). We use a regression model to understand how withincountry estimates change as a function of each of the factors, using the actual experiments across source regions and the counterfactual scenarios above. These impacts are cast in reasonable units to contextualize them. These findings also suggest that the physical system is a main driver of impacts at the local scale, and is not dominated by (e.g.) national level vulnerabilities or population distributions on average. The economic impacts are much more heterogeneous, likely due to the non-linearity in the damage function. Aerosol-driven cooling improves economic output in countries whose climatological temperature is above the economic optimum and damages output in those below.

\section{Contextualizing Aerosol Impacts}

In addition to the absolute damages (Table S5), we report the damages normalized by the total aerosol emissions perturbation (28.04 Tg of combined black carbon, organic carbon, and sulfate precursor for each scenario; Table S6). This allows us to assess the marginal damage per unit of emissions, which is the metric used in the inventories and accounting systems that typically drive policy, and provide a metric of damages from future incremental growth or mitigation of aerosol emissions in a given source region.

While aerosols and their precursors are emitted in many combustion processes, the relative production of these compounds (compared to $\mathrm{CO}_{2}$ ) varies by technology, feedstock, and combustion conditions and this is manifest in regional- and sectoral- scale differences in aerosol-to-ghg emissions ratios. ${ }^{47}$ We scale the equal-aerosol-emission results described above by converting from a per-Tg aerosol basis to a per- $\mathrm{CO}_{2}$ basis using either a global average 
aerosol-to- $\mathrm{CO}_{2}$ emissions ratio (Table S7) or a region-specific ratio (Table S8). Both ratios are drawn from the EDGAR global emissions inventory. ${ }^{47}$ These values are then locally-specific estimates of the impact of the concomitant aerosol emissions co-produced with a tonne of $\mathrm{CO}_{2}$ emissions from that region. We use all $\mathrm{CO}_{2}$ emissions here, including short-cycle $\mathrm{CO}_{2}$.

\section{Social Cost of Emission Calculations}

Policy analysts face a choice between accounting for benefits and damages across different units (e.g., premature deaths, tonnes of wheat, \$B GDP) using multi-attribute methods, or converting all benefits and damages to a common unit (typically currency) for a single-dimensional benefit-cost analysis. To facilitate the latter, we convert infant mortality and crop production impacts to \$USD values using standard methodologies (these are both presented in Tables S7-S8). We note that welfare impacts may differ considerably from monetary impacts (e.g. a lost tonne of wheat production likely reduces the welfare of a subsistence farmer than a large-scale producer).

To convert crop production changes to monetary values, we use an average crop price (across the four crops) of $\$ 300 /$ tonne, with Figure S16 showing a comparison between low and high values of \$100/tonne to \$400/tonne. We similarly convert deaths to monetary values using value of statistical life estimates from the literature. ${ }^{49-51}$ The main values presented in Tables S7 and S8 use Viscusi et. al. local values. However, we present Social Cost estimates based on an alternative region-specific $\mathrm{VSL}^{50}$ as well as using the global average VSL (\$1.8M) from Viscusi et. al. This global average is lower than, for example, the value used by the United States Environmental Protection Agency $(\$ 9.1 \mathrm{M}),{ }^{51}$ but numerous studies have shown a wide divergence in values across countries, and different weightings for infants versus other age cohorts. ${ }^{49,51,85}$ Per-emission damages are multiplied by these values to estimate the aerosol-related changes to the Social Cost of Carbon (both GSCC and CSCC). These parameters could take on a wide range of values, but as the goal here is to demonstrate how inclusion of co-emitted aerosols changes the social cost of a $\mathrm{CO}_{2}$ emission, we have used these low-to-moderate values for conservative estimates.

We use Ricke et. al. $2018^{4}$ as a baseline value for both the Global Social Cost of Carbon (GSCC) and the Country Social Cost of Carbon (CSCC). The GSCC represents the global total damages estimated to accrue from a marginal future tonne of $\mathrm{CO}_{2}$ emissions, and the $\mathrm{CSCC}$ represents the portion of those damages accruing to each country (irrespective of location of emission). Although Ricke et. al. represents a higher GSCC than values currently used in policy (and some others suggested in studies), it is ideal for comparison because it provides a self-consistent estimate of both country-level and global-level SCCs. We extend this methodology here by comparing the social costs (via infant mortality, crop production, and economic output) due to aerosol emissions that are co-produced with $\mathrm{CO}_{2}$ 
to the $\mathrm{CO}_{2}$-only values. Because aerosol atmospheric lifetimes are much shorter than $\mathrm{CO}_{2}$ (days-to-months versus decades-to-centuries), we assume a separability of time scales, and calculate aerosol-related damages on an annual basis, without any discounting.

\section{Significance Statement}

Carbon dioxide impacts earth's climate independent of where on the planet it is released into the atmosphere. However, most $\mathrm{CO}_{2}$ is co-emitted with other pollutants like aerosols and aerosol precursors that are not similarly longlived or well-mixed in the atmosphere. Here we show that emitting the same aerosols from different locations produces very different physical climate responses, which in turn create divergent impacts on human health, agricultural production, and economic output. Consideration of these co-emitted aerosols thus dramatically changes the social cost of carbon, with important geographic variations and linkages.

\section{Author Contributions}

All authors designed the research; G.P. designed and ran climate simulations, J.B. analyzed data with help from J.P. All authors wrote and revised the paper.

\section{Acknowledgments}

J.B., G.P., E.B., M.B., and S.H. were supported by the National Science Foundation NSF CNH-L \#1715557.

\section{Competing Interests}

The authors declare no competing interests. 


\section{References}

[1] Tol, R. S. The economic effects of climate change. Journal of economic perspectives 23, 29-51 (2009).

[2] Pizer, W. et al. Using and improving the social cost of carbon. Science 346, 1189-1190 (2014).

[3] Nordhaus, W. Estimates of the social cost of carbon: concepts and results from the dice-2013r model and alternative approaches. Journal of the Association of Environmental and Resource Economists 1, 273-312 (2014).

[4] Ricke, K., Drouet, L., Caldeira, K. \& Tavoni, M. Country-level social cost of carbon. Nature Climate Change 8, 895 (2018).

[5] Hsiang, S. et al. Estimating economic damage from climate change in the united states. Science 356, 13621369 (2017).

[6] Shindell, D. \& Faluvegi, G. Climate response to regional radiative forcing during the twentieth century. Nature Geoscience 2, 294-300 (2009). URL http://www . nature.com/ngeo/journal/v2/n4/abs/ngeo473. html.

[7] Shindell, D. T. Inhomogeneous forcing and transient climate sensitivity. Nature Climate Change 4, 274-277 (2014). URL http://www . nature.com/nclimate/journal/vaop/ncurrent/full/nclimate2136. html.

[8] Persad, G. G. \& Caldeira, K. Divergent global-scale temperature effects from identical aerosols emitted in different regions. Nature Communications 9, 3289 (2018). URL https://www.nature.com/articles/ s41467-018-05838-6.

[9] Shindell, D. et al. Climate forcing and air quality change due to regional emissions reductions by economic sector. Atmospheric Chemistry and Physics 8, 7101-7113 (2008).

[10] Wallack, J. S. \& Ramanathan, V. The Other Climate Changers: Why Black Carbon and Ozone Also Matter. Foreign Affairs 5, 105-113 (2009).

[11] UNEP. Integrated Assessment of Black Carbon and Tropospheric Ozone: Summary for Decision Makers. Tech. Rep., United Nations Environment Programme and World Meteorological Organization (2011).

[12] Burney, J. \& Ramanathan, V. Recent climate and air pollution impacts on indian agriculture. Proceedings of the National Academy of Sciences 111, 16319-16324 (2014). 
[13] Smith, K. R. et al. Public health benefits of strategies to reduce greenhouse-gas emissions: health implications of short-lived greenhouse pollutants. The Lancet 374, 2091-2103 (2009).

[14] Anenberg, S. C. et al. Global air quality and health co-benefits of mitigating near-term climate change through methane and black carbon emission controls. Environmental health perspectives 120, 831-839 (2012).

[15] West, J. J. et al. Co-benefits of mitigating global greenhouse gas emissions for future air quality and human health. Nature climate change 3, 885-889 (2013).

[16] Tibrewal, K. \& Venkataraman, C. Climate co-benefits of air quality and clean energy policy in india. Nature Sustainability 1-9 (2020).

[17] Balbus, J. M., Greenblatt, J. B., Chari, R., Millstein, D. \& Ebi, K. L. A wedge-based approach to estimating health co-benefits of climate change mitigation activities in the united states. Climatic change 127, 199-210 (2014).

[18] Burney, J. A. The downstream air pollution impacts of the transition from coal to natural gas in the united states. Nature Sustainability 3, 152-160 (2020).

[19] Driscoll, C. T. et al. Us power plant carbon standards and clean air and health co-benefits. Nature Climate Change 5, 535-540 (2015).

[20] Shindell, D. T. The social cost of atmospheric release. Climatic Change 130, 313-326 (2015).

[21] Rao, S. et al. A multi-model assessment of the co-benefits of climate mitigation for global air quality. Environmental Research Letters 11, 124013 (2016).

[22] Markandya, A. et al. Health co-benefits from air pollution and mitigation costs of the paris agreement: a modelling study. The Lancet Planetary Health 2, e126-e133 (2018).

[23] Scovronick, N. et al. The impact of human health co-benefits on evaluations of global climate policy. Nature communications 10, 2095 (2019).

[24] Tschofen, P., Azevedo, I. L. \& Muller, N. Z. Fine particulate matter damages and value added in the us economy. Proceedings of the National Academy of Sciences 116, 19857-19862 (2019).

[25] Shindell, D. et al. Climate, health, agricultural and economic impacts of tighter vehicle-emission standards. Nature Climate Change 1, 59 (2011).

[26] Shindell, D. et al. Simultaneously mitigating near-term climate change and improving human health and food security. Science 335, 183-189 (2012). 
[27] Shindell, D., Faluvegi, G., Seltzer, K. \& Shindell, C. Quantified, localized health benefits of accelerated carbon dioxide emissions reductions. Nature climate change 8, 291-295 (2018).

[28] Lelieveld, J. et al. Effects of fossil fuel and total anthropogenic emission removal on public health and climate. Proceedings of the National Academy of Sciences 116, 7192-7197 (2019).

[29] Shindell, D. T., Voulgarakis, A., Faluvegi, G. \& Milly, G. Precipitation response to regional radiative forcing. Atmos. Chem. Phys. 12, 6969-6982 (2012). URL http://www . atmos-chem-phys.net/12/6969/2012/.

[30] Wang, H., Xie, S.-P. \& Liu, Q. Comparison of climate response to anthropogenic aerosol versus greenhouse gas forcing: Distinct patterns. Journal of Climate 29, 5175-5188 (2016).

[31] Aamaas, B., Berntsen, T. K., Fuglestvedt, J. S., Shine, K. P. \& Collins, W. J. Regional temperature change potentials for short-lived climate forcers based on radiative forcing from multiple models. Atmos. Chem. Phys. 17, 10795-10809 (2017). URL https://www . atmos-chem-phys.net/17/10795/2017/.

[32] Westervelt, D. M. et al. Connecting regional aerosol emissions reductions to local and remote precipitation responses. Atmospheric Chemistry and Physics 18, 12461-12475 (2018). URL https://www. atmos-chem-phys.net/18/12461/2018/acp-18-12461-2018-discussion.html.

[33] Persad, G. G. \& Caldeira, K. Divergent global-scale temperature effects from identical aerosols emitted in different regions. Nature Communications 9, 3289 (2018).

[34] Myhre, G. et al. Anthropogenic and Natural Radiative Forcing. In Stocker, T. F. et al. (eds.) Climate Change 2013: The Physical Science Basis. Contribution of Working Group I to the Fifth Assessment Report of the Intergovernmental Panel on Climate Change (Cambridge University Press, Cambridge, United Kingdom and New York, NY, USA, 2013).

[35] Snider, G. et al. Spartan: a global network to evaluate and enhance satellite-based estimates of ground-level particulate matter for global health applications. Atmospheric Measurement Techniques 8, 505-521 (2015).

[36] Weagle, C. L. et al. Global sources of fine particulate matter: interpretation of pm2. 5 chemical composition observed by spartan using a global chemical transport model. Environmental Science \& Technology 52, 1167011681 (2018).

[37] Heft-Neal, S., Burney, J., Bendavid, E. \& Burke, M. Robust relationship between air quality and infant mortality in africa. Nature 559, 254 (2018).

[38] Proctor, J., Hsiang, S., Burney, J., Burke, M. \& Schlenker, W. Estimating global agricultural effects of geoengineering using volcanic eruptions. Nature 1 (2018). 
[39] Burke, M., Hsiang, S. M. \& Miguel, E. Global non-linear effect of temperature on economic production. Nature 527, 235 (2015).

[40] Stohl, A., Eckhardt, S., Forster, C., James, P. \& Spichtinger, N. On the pathways and timescales of intercontinental air pollution transport. Journal of Geophysical Research: Atmospheres 107, ACH 6-1-ACH 617 (2002). URL https://agupubs.onlinelibrary.wiley.com/doi/abs/10 . 1029/2001JD001396. _eprint: https://agupubs.onlinelibrary.wiley.com/doi/pdf/10.1029/2001JD001396.

[41] Shindell, D. T. et al. A multi-model assessment of pollution transport to the Arctic. Atmospheric Chemistry and Physics 8, 5353-5372 (2008). URL https://doi .org/10.5194/acp-8-5353-2008. Num Pages: 20 Number: 17.

[42] Held, I. M. \& Soden, B. J. Robust responses of the hydrological cycle to global warming. Journal of Climate 19, 5686-5699 (2006). URL http://journals . ametsoc.org/doi/pdf/10. 1175/JCLI3990.1.

[43] Institute for Health Metrics and Evalulation. GBD Compare data visualization (2017). URL http://vizhub. healthdata.org/gbd-compare.

[44] Bell, M. L., Ebisu, K. \& Belanger, K. Ambient air pollution and low birth weight in Connecticut and Massachusetts. Environmental Health Perspectives 115, 1118-1124 (2007).

[45] Pope, D. P. et al. Risk of low birth weight and stillbirth associated with indoor air pollution from solid fuel use in developing countries. Epidemiologic Reviews 32, 70-81 (2010).

[46] Schlenker, W. \& Lobell, D. B. Robust negative impacts of climate change on African agriculture. Environmental Research Letters 5, 014010 (2010). URL https: //doi .org/10 . 1088\%2F 1748-9326\%2F 5\%2F 1\% 2F014010. Publisher: IOP Publishing.

[47] European Commission and Joint Research Centre (JRC) and Netherlands Environmental Assessment Agency (PBL). Emission Database for Global Atmospheric Research (EDGAR), release version 4.2 (2012). URL http://edgar.jrc.ec.europa.eu.

[48] Food \& of the United Nations (FAO), A. O. URL https://faostat . fao.org.

[49] Viscusi, W. K. \& Masterman, C. J. Income elasticities and global values of a statistical life. Journal of BenefitCost Analysis 8, 226-250 (2017).

[50] Robinson, L. A., Hammitt, J. K. \& O'Keeffe, L. Valuing mortality risk reductions in global benefit-cost analysis. Journal of Benefit-Cost Analysis 10, 15-50 (2019).

[51] United States Environmental Protection Agency (EPA). Mortality Risk Valuation (2019). URL https://www. epa.gov/environmental-economics/mortality-risk-valuation. 
[52] Burney, J. A., Kennel, C. F. \& Victor, D. G. Getting serious about the new realities of global climate change. Bulletin of the Atomic Scientists 69, 49-57 (2013).

[53] Smith, K. R. et al. Public health benefits of strategies to reduce greenhouse-gas emissions: health implications of short-lived greenhouse pollutants. The lancet 374, 2091-2103 (2009).

[54] Aakre, S., Kallbekken, S., Van Dingenen, R. \& Victor, D. G. Incentives for small clubs of arctic countries to limit black carbon and methane emissions. Nature Climate Change 8, 85 (2018).

[55] Wang, R. et al. Exposure to ambient black carbon derived from a unique inventory and high-resolution model. Proceedings of the National Academy of Sciences 111, 2459-2463 (2014).

[56] Gadhavi, H. et al. Evaluation of black carbon emission inventories using a lagrangian dispersion model-a case study over southern india. Atmospheric Chemistry and Physics 15, 1447-1461 (2015).

[57] Carter, T. S. et al. How emissions uncertainty influences the distribution and radiative impacts of smoke from fires in north america. Atmospheric Chemistry and Physics (2020).

[58] Graff Zivin, J. \& Neidell, M. The Impact of Pollution on Worker Productivity. American Economic Review 102, 3652-73 (2012). URL http://www . aeaweb.org/articles.php?doi=10 .1257/aer . 102 .7 . 3652.

[59] Bharadwaj, P., Gibson, M., Zivin, J. G. \& Neilson, C. A. Gray Matters: Fetal Pollution Exposure and Human Capital Formation. National Bureau of Economic Research Working Paper Series No. 20662 (2014). URL http://www .nber.org/papers/w20662.

[60] Knohl, A. \& Baldocchi, D. D. Effects of diffuse radiation on canopy gas exchange processes in a forest ecosystem. Journal of Geophysical Research: Biogeosciences 113 (2008).

[61] Rap, A. et al. Enhanced global primary production by biogenic aerosol via diffuse radiation fertilization. $\mathrm{Na}$ ture Geoscience 11, 640-644 (2018).

[62] Hemes, K. S., Verfaillie, J. \& Baldocchi, D. D. Wildfire-smoke aerosols lead to increased light use efficiency among agricultural and restored wetland land uses in california's central valley. Journal of Geophysical Research: Biogeosciences 125, e2019JG005380 (2020).

[63] Carleton, T. A. \& Hsiang, S. M. Social and economic impacts of climate. Science 353 (2016).

[64] Hsiang, S. M., Meng, K. C. \& Cane, M. A. Civil conflicts are associated with the global climate. Nature 476, 438-441 (2011).

[65] Lamarque, J.-F. et al. Historical (1850-2000) gridded anthropogenic and biomass burning emissions of reactive gases and aerosols: methodology and application. Atmos. Chem. Phys. 10, 7017-7039 (2010). URL http: //www. atmos-chem-phys.net/10/7017/2010/. 
[66] Takemura, T. Distributions and climate effects of atmospheric aerosols from the preindustrial era to 2100 along representative concentration pathways (rcps) simulated using the global aerosol model sprintars. Atmospheric Chemistry and Physics 12, 11555-11572 (2012).

[67] Lund, M. T., Myhre, G. \& Samset, B. H. Anthropogenic aerosol forcing under the Shared Socioeconomic Pathways. Atmospheric Chemistry and Physics 19, 13827-13839 (2019). URL https: //acp. copernicus . org/articles/19/13827/2019/. Publisher: Copernicus GmbH.

[68] Spracklen, D. V. \& Rap, A. Natural aerosol-climate feedbacks suppressed by anthropogenic aerosol. Geophysical Research Letters n/a-n/a (2013). URL http://onlinelibrary.wiley.com/doi/10.1002/ 2013GLQ57966/abstract.

[69] Carslaw, K. S. et al. Large contribution of natural aerosols to uncertainty in indirect forcing. Nature 503, 67-71 (2013). URL http://www. nature.com/nature/journal/v503/n7474/abs/nature12674.html.

[70] Carslaw, K. S. et al. A review of natural aerosol interactions and feedbacks within the Earth system. Atmos. Chem. Phys. 10, 1701-1737 (2010). URL http: //www . atmos-chem-phys .net/10/1701/2010/.

[71] Carslaw, K. S. et al. Aerosols in the Pre-industrial Atmosphere. Current Climate Change Reports 3, 1-15 (2017). URL https://link . springer . com/article/10.1007/s40641-017-0061-2. Company: Springer Distributor: Springer Institution: Springer Label: Springer Number: 1 Publisher: Springer International Publishing.

[72] O’Neill, B. C. et al. The roads ahead: Narratives for shared socioeconomic pathways describing world futures in the 21st century. Global Environmental Change (2015). URL http://www. sciencedirect. com/ science/article/pii/S0959378015000060.

[73] Liu, X. et al. Toward a minimal representation of aerosols in climate models: description and evaluation in the Community Atmosphere Model CAM5. Geoscientific Model Development 5, 709-739 (2012). URL https: //www.geosci-model-dev.net/5/709/2012/.

[74] Ghan, S. J. et al. Toward a Minimal Representation of Aerosols in Climate Models: Comparative Decomposition of Aerosol Direct, Semidirect, and Indirect Radiative Forcing. Journal of Climate 25, 6461-6476 (2012). URL http://journals . ametsoc.org/doi/abs/10.1175/JCLI-D-11-00650.1.

[75] Koutroulis, A. G., Grillakis, M. G., Tsanis, I. K. \& Papadimitriou, L. Evaluation of precipitation and temperature simulation performance of the CMIP3 and CMIP5 historical experiments. Climate Dynamics 47, 1881-1898 (2016). URL https://link.springer.com/article/10.1007/s00382-015-2938-x. 
[76] Myhre, G. et al. PDRMIP: A Precipitation Driver and Response Model Intercomparison Project—Protocol and Preliminary Results. Bulletin of the American Meteorological Society 98, 1185-1198 (2016). URL http: //journals.ametsoc.org/doi/10.1175/BAMS-D-16-0019.1.

[77] Collins, W. J. et al. AerChemMIP: quantifying the effects of chemistry and aerosols in CMIP6. Geoscientific Model Development 10, 585-607 (2017). URL https://gmd. copernicus . org/articles/10/585/2017/. Publisher: Copernicus GmbH.

[78] He, G., Fan, M. \& Zhou, M. The effect of air pollution on mortality in china: Evidence from the 2008 beijing olympic games. Journal of Environmental Economics and Management 79, 18-39 (2016).

[79] Arceo, E., Hanna, R. \& Oliva, P. Does the effect of pollution on infant mortality differ between developing and developed countries? evidence from mexico city. The Economic Journal 126, 257-280 (2016).

[80] Chay, K. Y. \& Greenstone, M. The impact of air pollution on infant mortality: evidence from geographic variation in pollution shocks induced by a recession. The Quarterly Journal of Economics 118, 1121-1167 (2003).

[81] Center for International Earth Science Information Network - CIESIN - Columbia University. Poverty Mapping Project: Global Subnational Infant Mortality Rates (2015). URL https://doi .org/10.7927/H4PN93J J.

[82] Center for International Earth Science Information Network - CIESIN - Columbia University. Gridded Population of the World, Version 4 (GPWv4): Population Count, Revision 11 (2018). URL https: //doi .org/10. 7927/H4JW8BX5.

[83] Monfreda, C., Ramankutty, N. \& Foley, J. A. Farming the planet: 2. geographic distribution of crop areas, yields, physiological types, and net primary production in the year 2000. Global biogeochemical cycles 22 (2008).

[84] Sacks, W. J., Deryng, D., Foley, J. A. \& Ramankutty, N. Crop planting dates: an analysis of global patterns. Global Ecology and Biogeography 19, 607-620 (2010).

[85] Lindhjem, H., Navrud, S., Braathen, N. A. \& Biausque, V. Valuing mortality risk reductions from environmental, transport, and health policies: A global meta-analysis of stated preference studies. Risk Analysis: An International Journal 31, 1381-1407 (2011). 


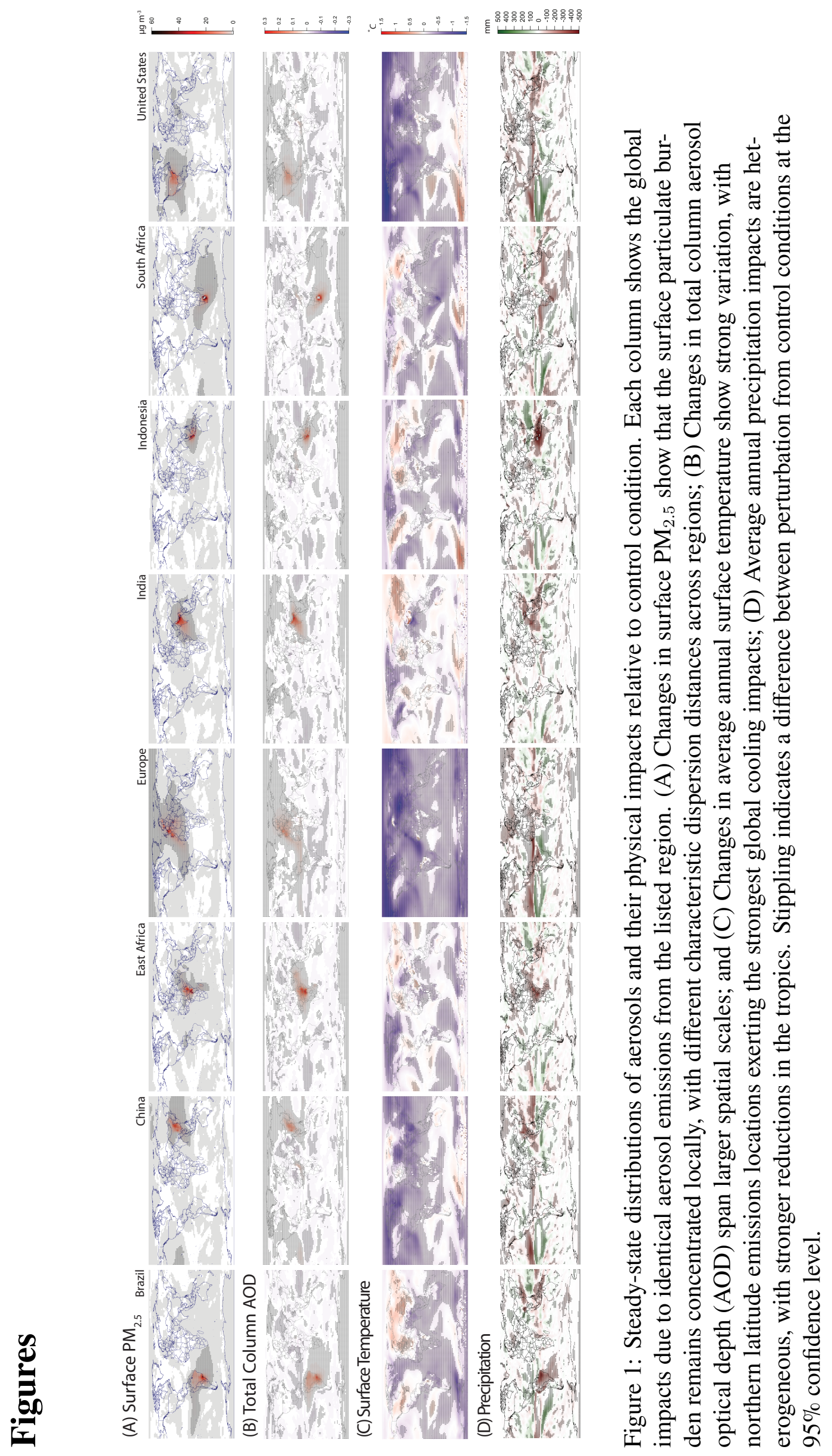


(A) Emissions Regions

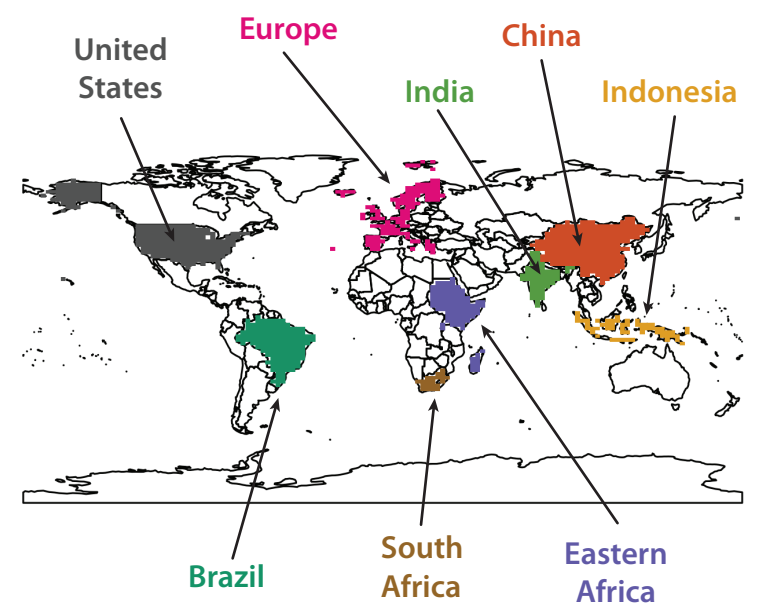

(C) Localization of Crop Impacts

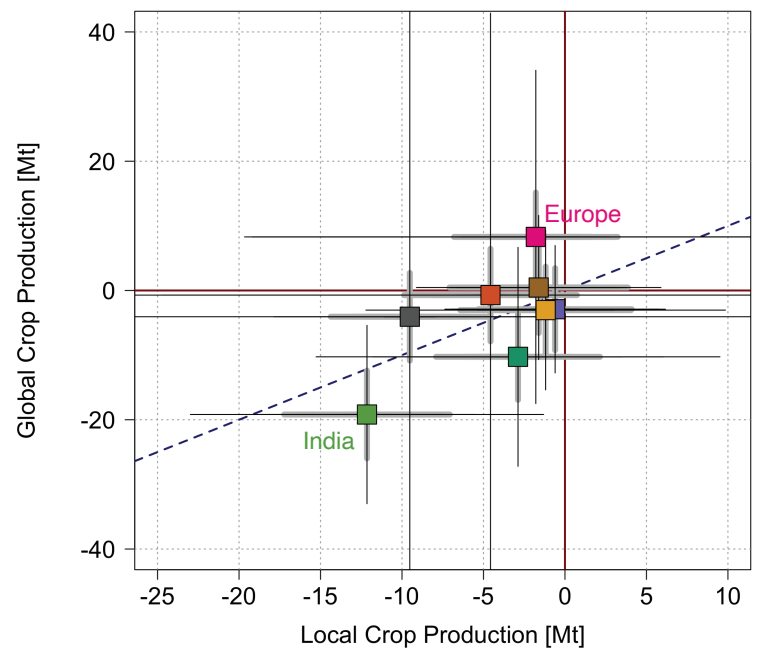

(B) Localization of Infant Mortality Impacts

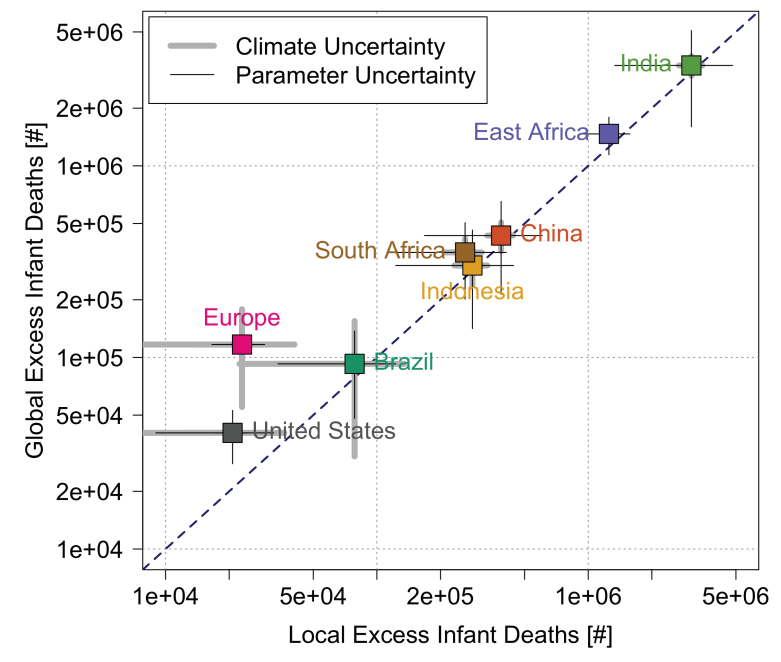

(D) Localization of GDP Impacts

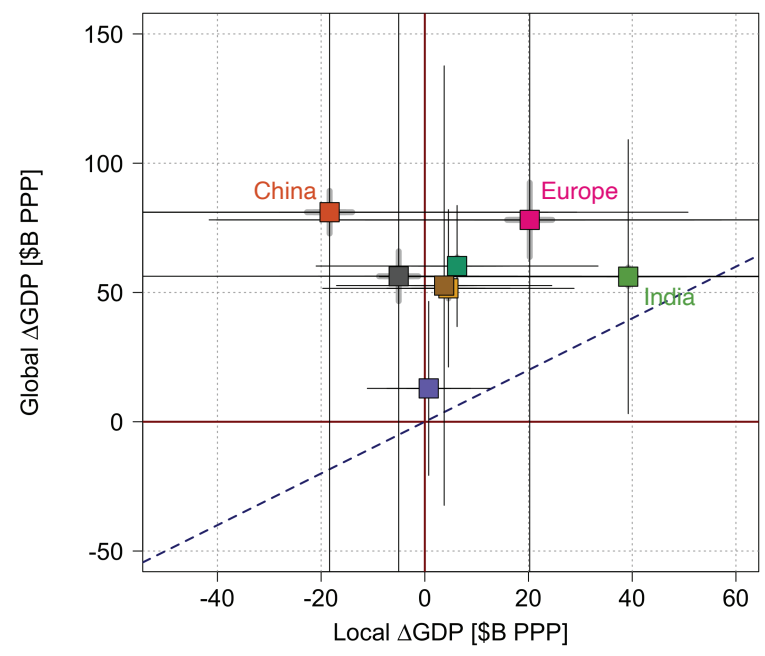

Figure 2: Social impacts from each source region (A) relative to control conditions, aggregated to local (within the emissions region) and global totals. (B) Excess infant deaths are large proximal to the source, though aerosol transport over populated and/or vulnerable regions creates distal impacts. (C) The geographic distribution of crop production changes varies widely, with heterogeneous radiation, temperature, and precipitation effects creating substantial distal impacts. (D) Economic impacts include both positive and negative effects, with positive impacts arise from cooling of countries above the economically optimal temperature in the control condition. Location on the 1:1 line indicates purely localized impacts (local=global), while departures above or below the line indicate exported effects. Grey error bars show the uncertainty $(95 \% \mathrm{CI})$ due to natural climate variability present in simulations, and black bars show uncertainty $(95 \% \mathrm{CI})$ from damage function parameter estimation. Point colors for (B-D) correspond to the emissions regions colors in $(\mathrm{A})$ 


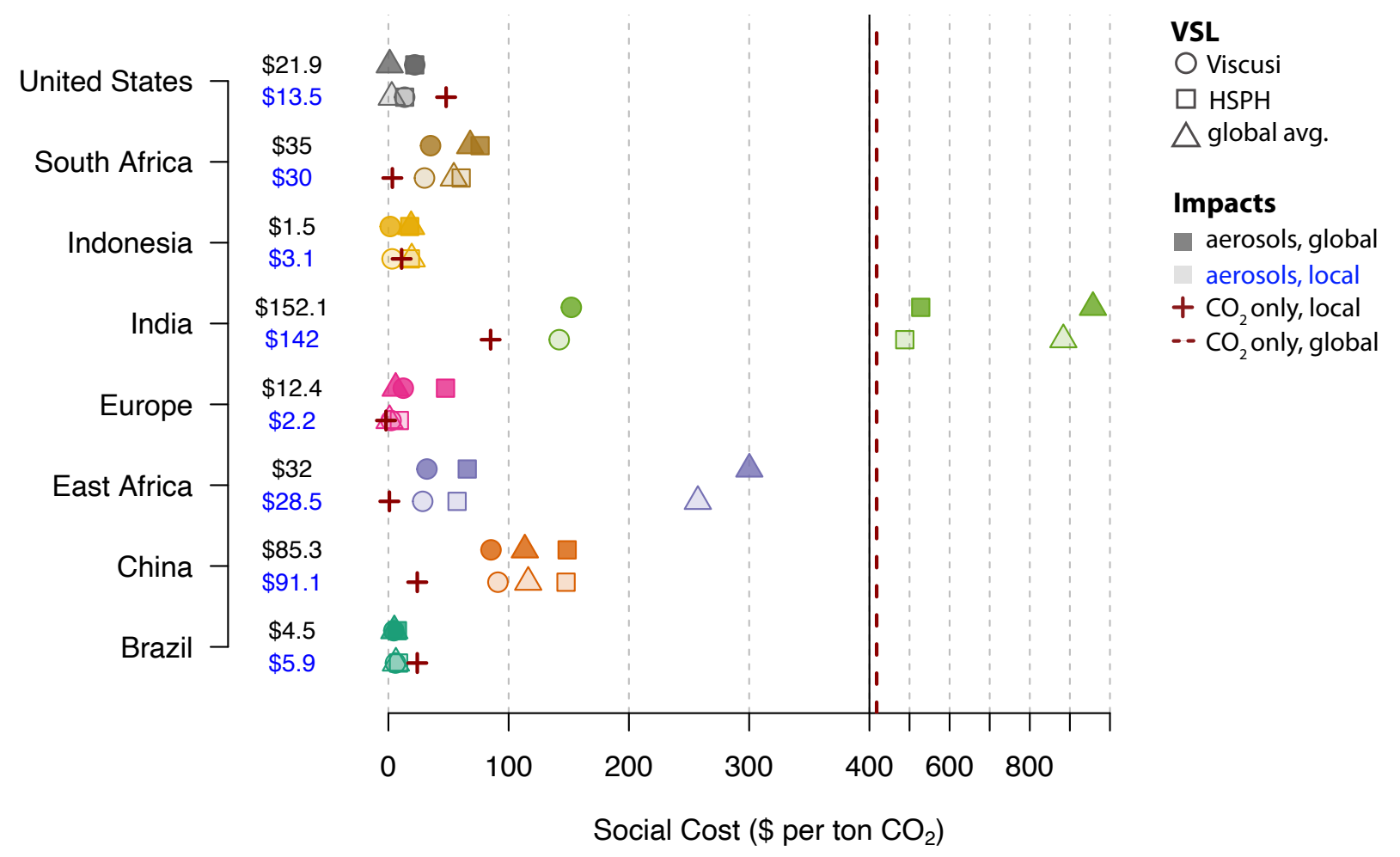

Figure 3: The per- $\mathrm{CO}_{2}$ normalized aerosol Social Costs estimated in this study. Impacts are the sum of GDP effects and infant mortality (GDP is assumed to include agricultural impacts, but a comparison of these is shown in Figure S16). Social costs are calculated here using a regionallyspecific aerosol-to- $\mathrm{CO}_{2}$ emission ratio to scale the per-emission impacts derived from our experiments, and three different VSL values. VSL values from Viscusi et. al. ${ }^{49}$ (circles) are derived by scaling USEPA values to other countries based on their relative GNI and local stated preferences about willingness to pay for reduced risk of death. VSLs from the Harvard School of Public Health (HSPH, squares, from Robinson et. al. ${ }^{50}$ ), scale US and OECD Values based on different elasticities (here, 1). Finally, triangles show the social cost of aerosols using the global average VSL ( $\$ 1.8 \mathrm{M}$ ) from Viscusi et. al. The dashed red line is the central value for the Global Social Cost of Carbon (GSCC, $\$ 418$ per tonne of $\mathrm{CO}_{2}$ ) from Ricke et. al. ${ }^{4}$ Red crosses show the $\mathrm{CO}_{2}$-only Country-level Social Cost of Carbon (CSCC) from the same source, or the portion of $\mathrm{CO}_{2}$-related damages that accrue locally. In many cases, local aerosol social costs exceed the CSCC. Dollar values in black and blue correspond to the global and local aerosol impacts, respectively, calculated with Viscusi VSL; Table S9 shows all values. $\mathrm{CO}_{2}$-normalized local and global impacts from aerosol emissions from the 8 regions are summarized in Tables S8 and S7 (where impacts are scaled using a global aerosol-to- $\mathrm{CO}_{2}$ emission ratio instead). 


\section{. Extended Data for}

3 Geographically-resolved social cost of anthropogenic emissions accounting for both direct and climate-mediated effects

5 Jennifer Burney, Geeta Persad, Jonathan Proctor, Eran Bendavid, Marshall Burke, Sam Heft-Neal

6 Corresponding Authors:

Jennifer Burney: jburney@ucsd.edu

8 Geeta Persad: Geeta.Persad@jsg.utexas.edu

9 This PDF file includes:

Figs. ED1 to ED16

Tables ED1 to ED12

ED References 

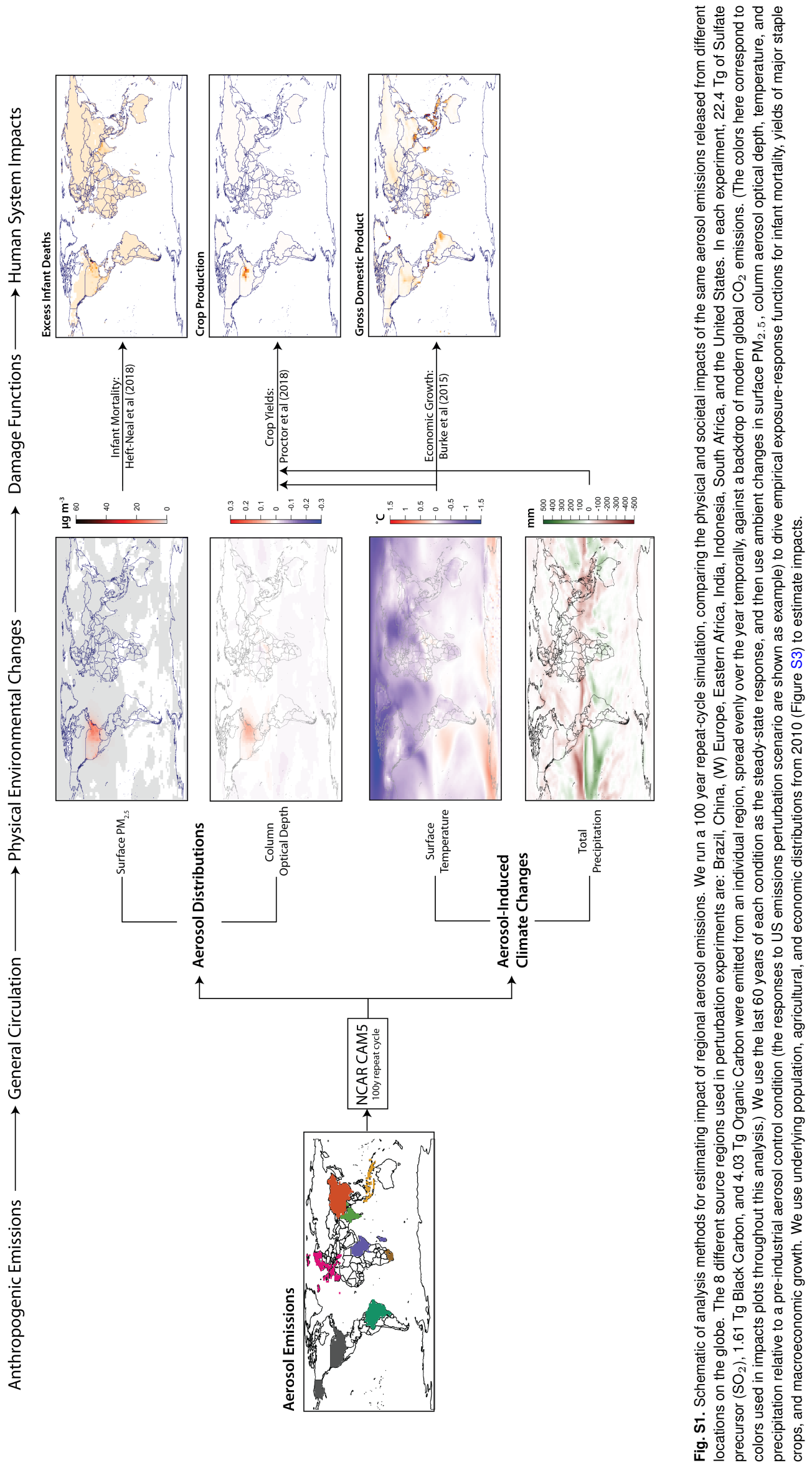

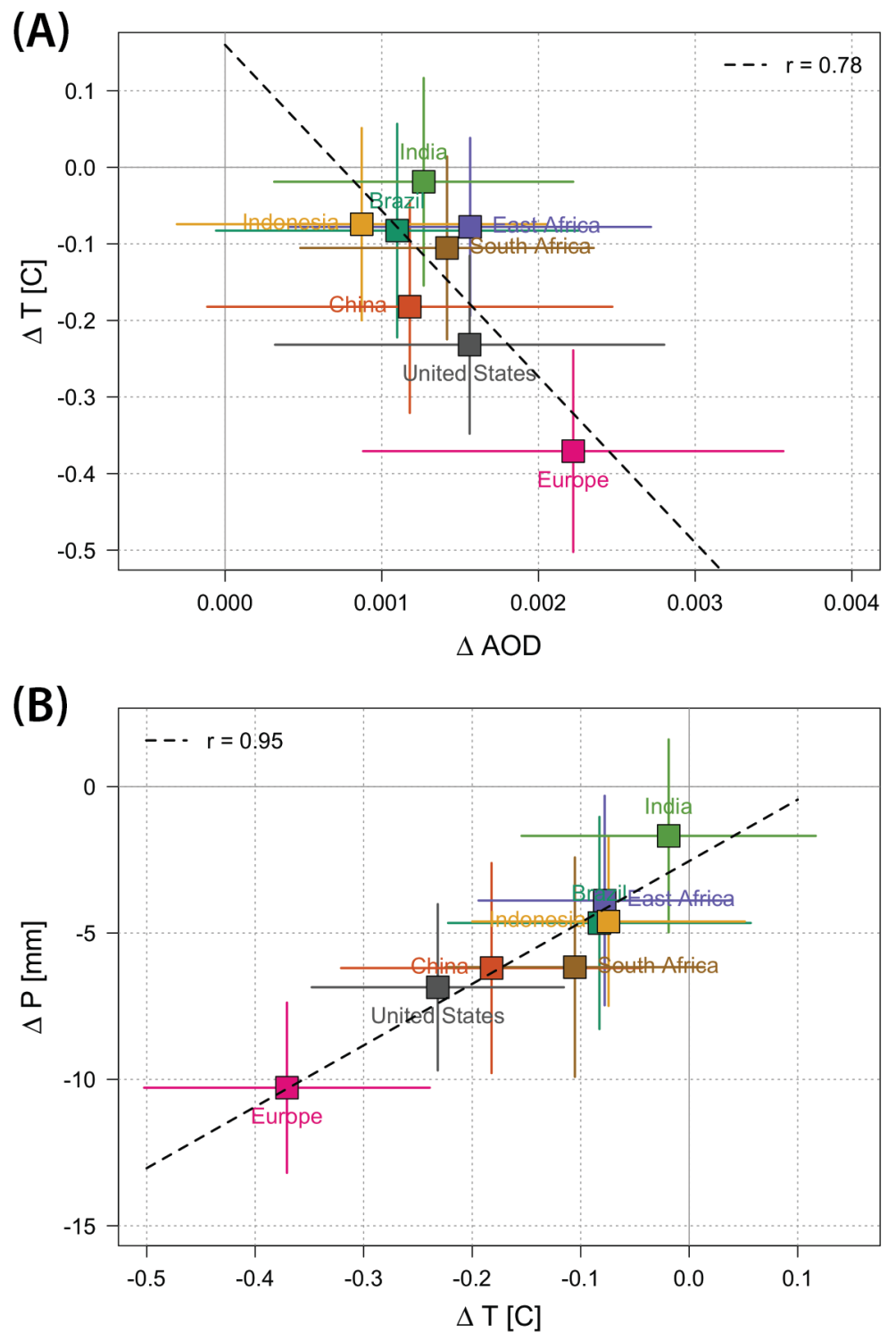

Fig. S2. Physical correlations between global-mean responses of aerosol optical depth, temperature, and precipitation for each experimental condition relative to control. Global mean responses for AOD across emitting regions vary by a factor of $\sim 2.5$, while temperature and precipitation vary by approximately an order of magnitude. (A) Changes in AOD are strongly correlated with cooling (strong direct radiative effects), and (B) global-mean precipitation reductions are strongly correlated with the overall cooling due to thermodynamic constraints on the hydrologic cycle. 
(A) Distributions

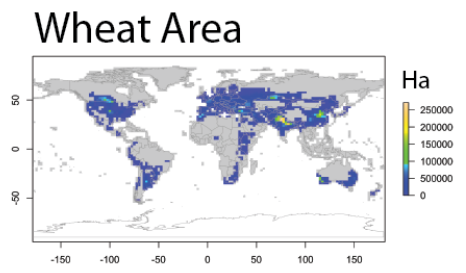

Maize Area

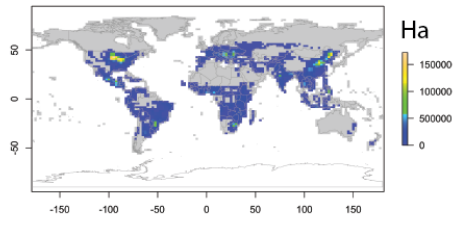

Soybean Area

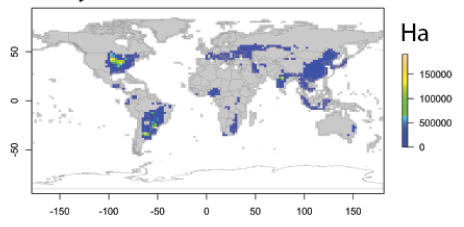

Rice Area
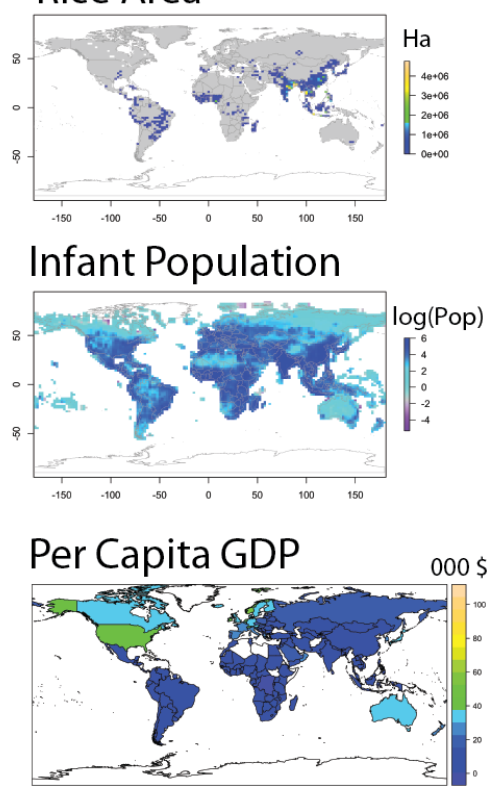

(B) Baseline Values
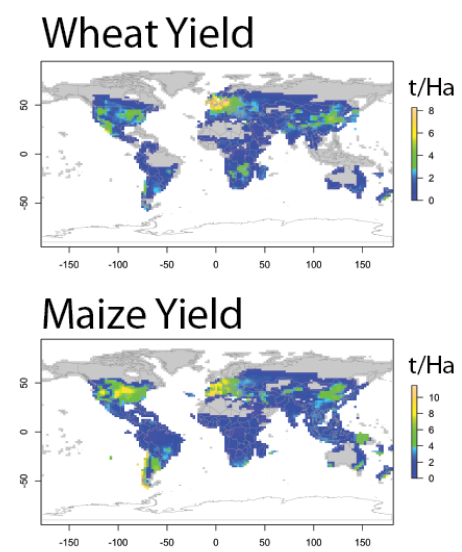

Soybean Yield

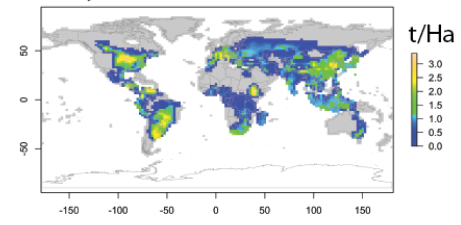

Rice Yield

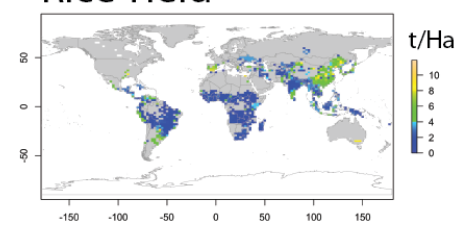

Infant Mortality Rate
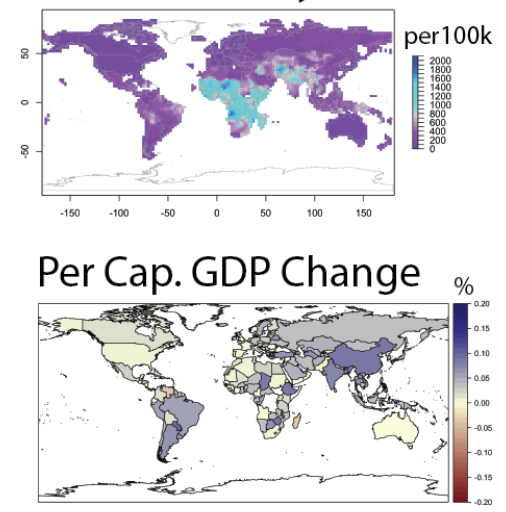

Fig. S3. Baseline distributions of crop areas and yields (year 2000), infant population density and mortality rate (year 2010), and per capita GDP and GDP growth (year 2010) used to estimate impacts. 


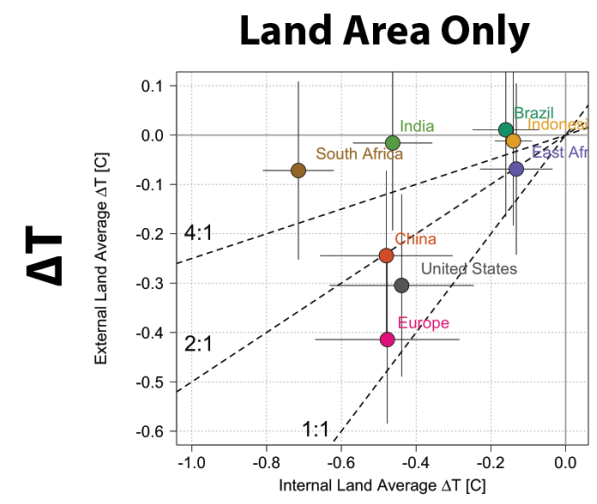

\section{Population Weighted}
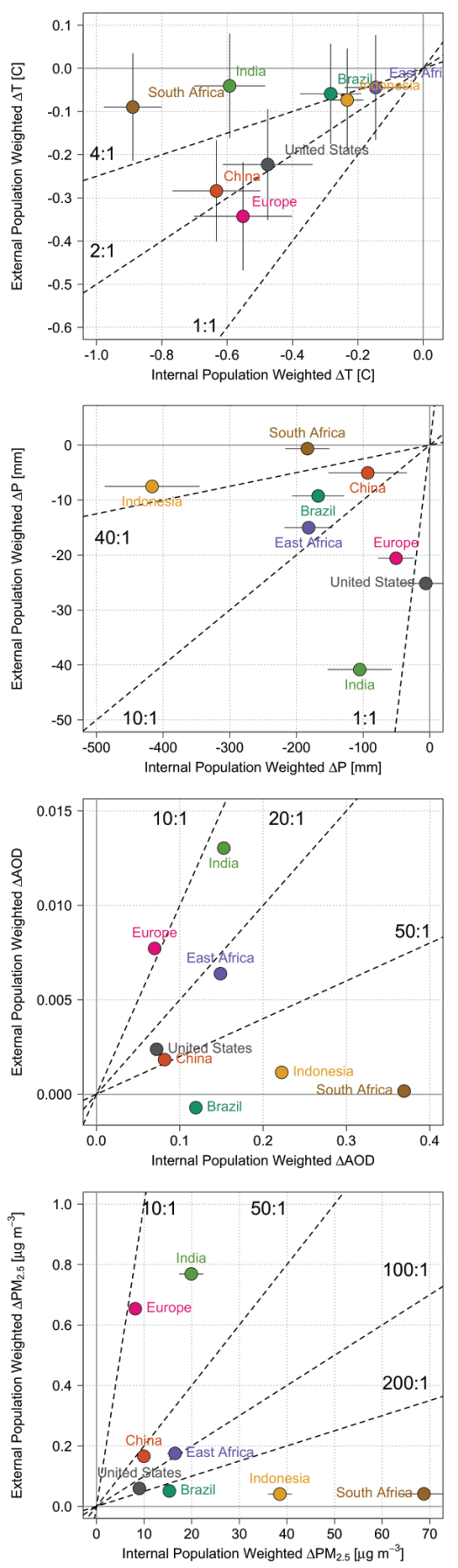

\section{Crop Area Weighted}
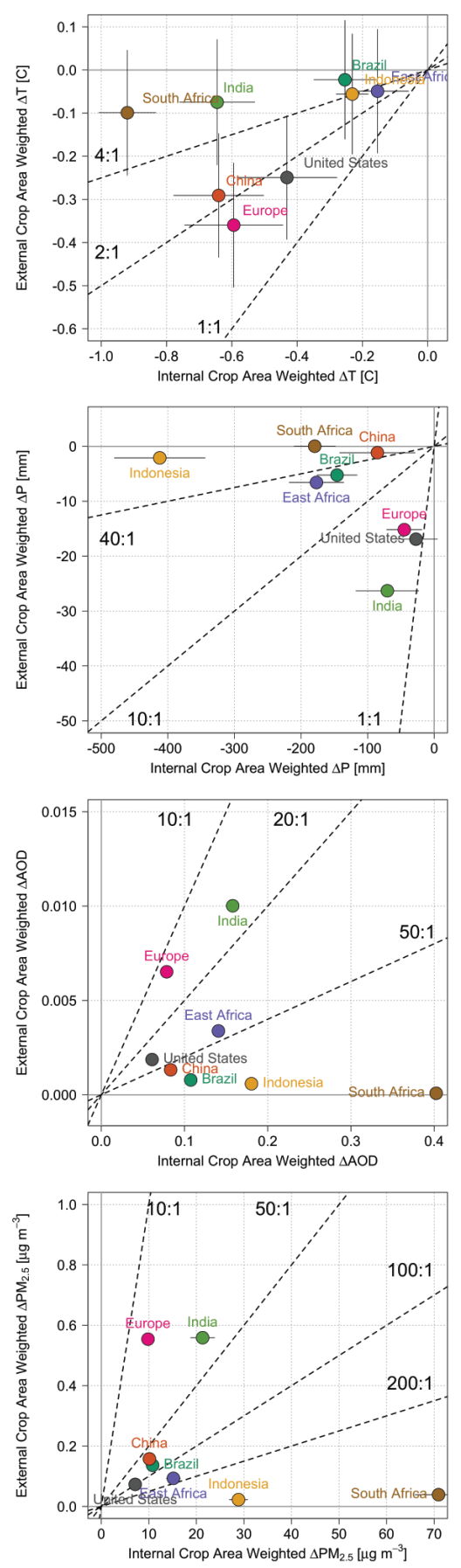

Fig. S4. Internal impacts (Local to emitting region) versus External impacts (Global - Local) of aerosol emissions from different regions. Effects are shown for (top to bottom) temperature, precipitation, column $\mathrm{AOD}$, and surface $\mathrm{PM}_{2.5}$ relative to control conditions. The left column shows simple land average exposure changes and thus encapsulates the variation in the physical system response across regions. The central column shows population-weighted average exposure changes, and the right column shows crop-area weighted average exposure changes. The differences between the center and right columns and the left column thus illustrate how the distribution of populations and land use interact with the physical system to either magnify or mitigate vulnerability. 

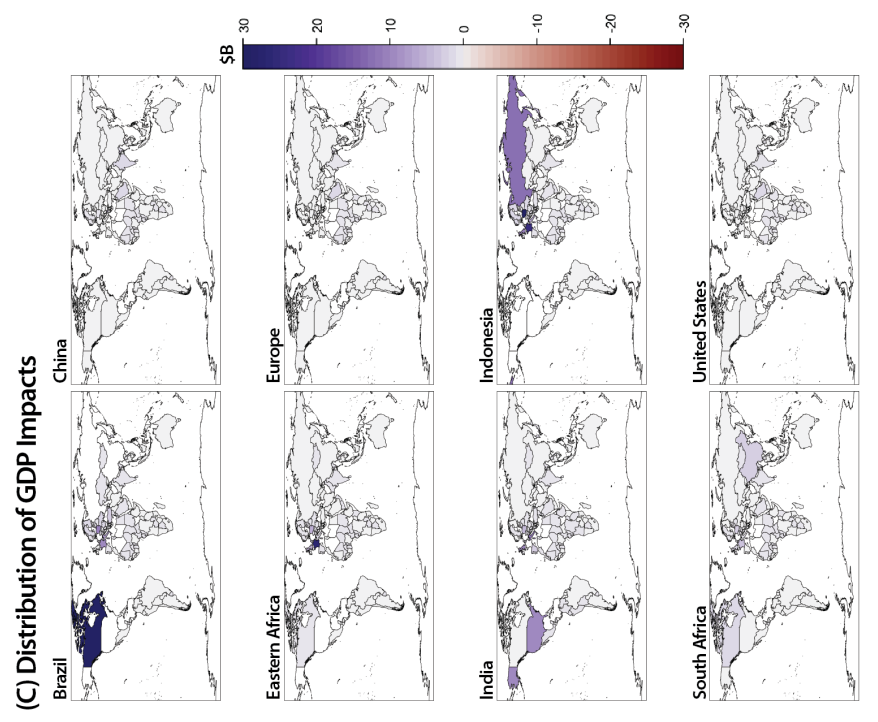

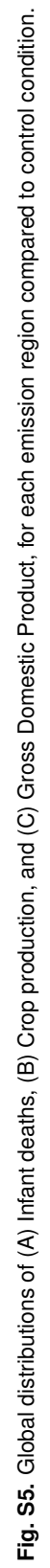
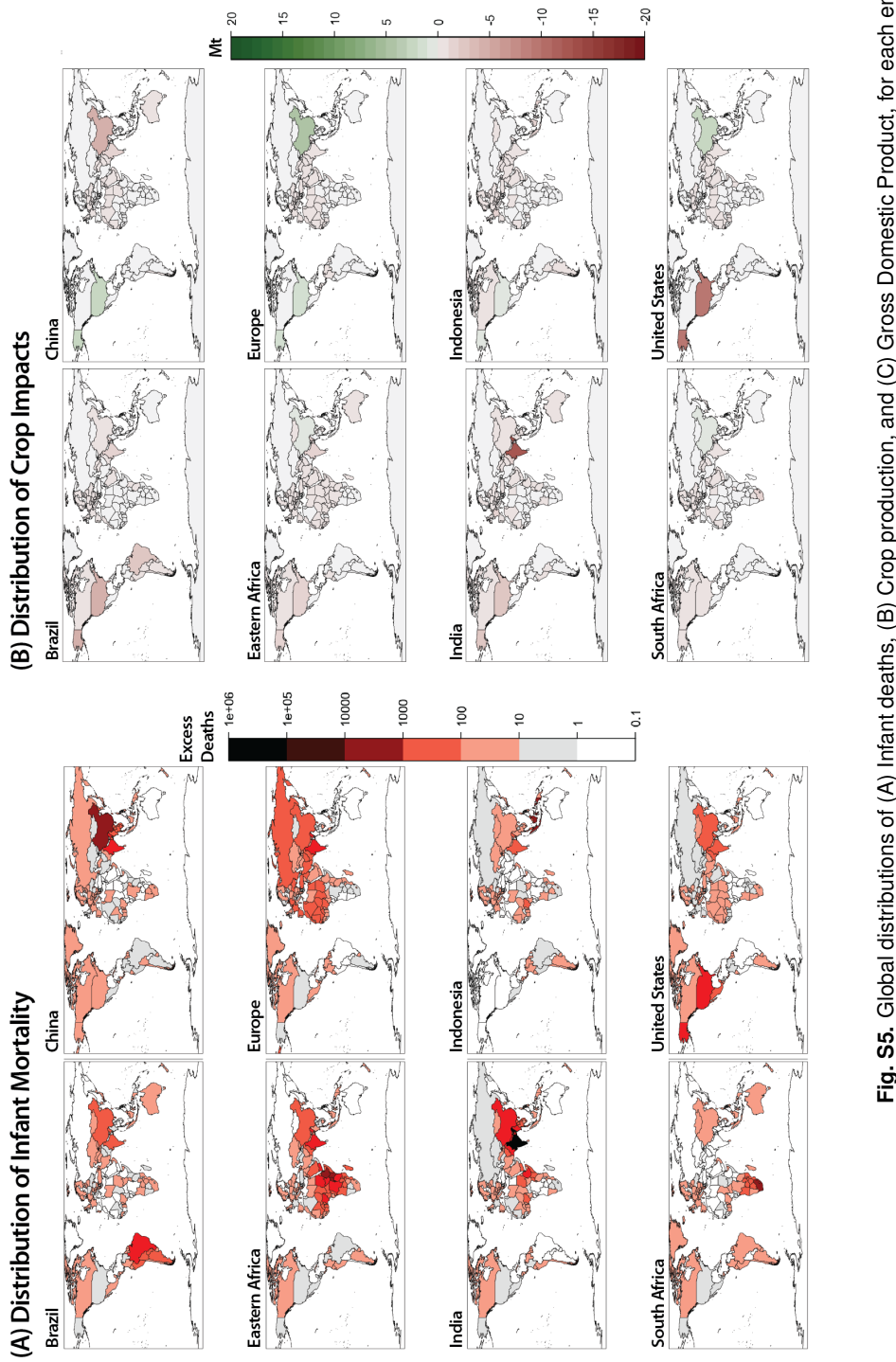

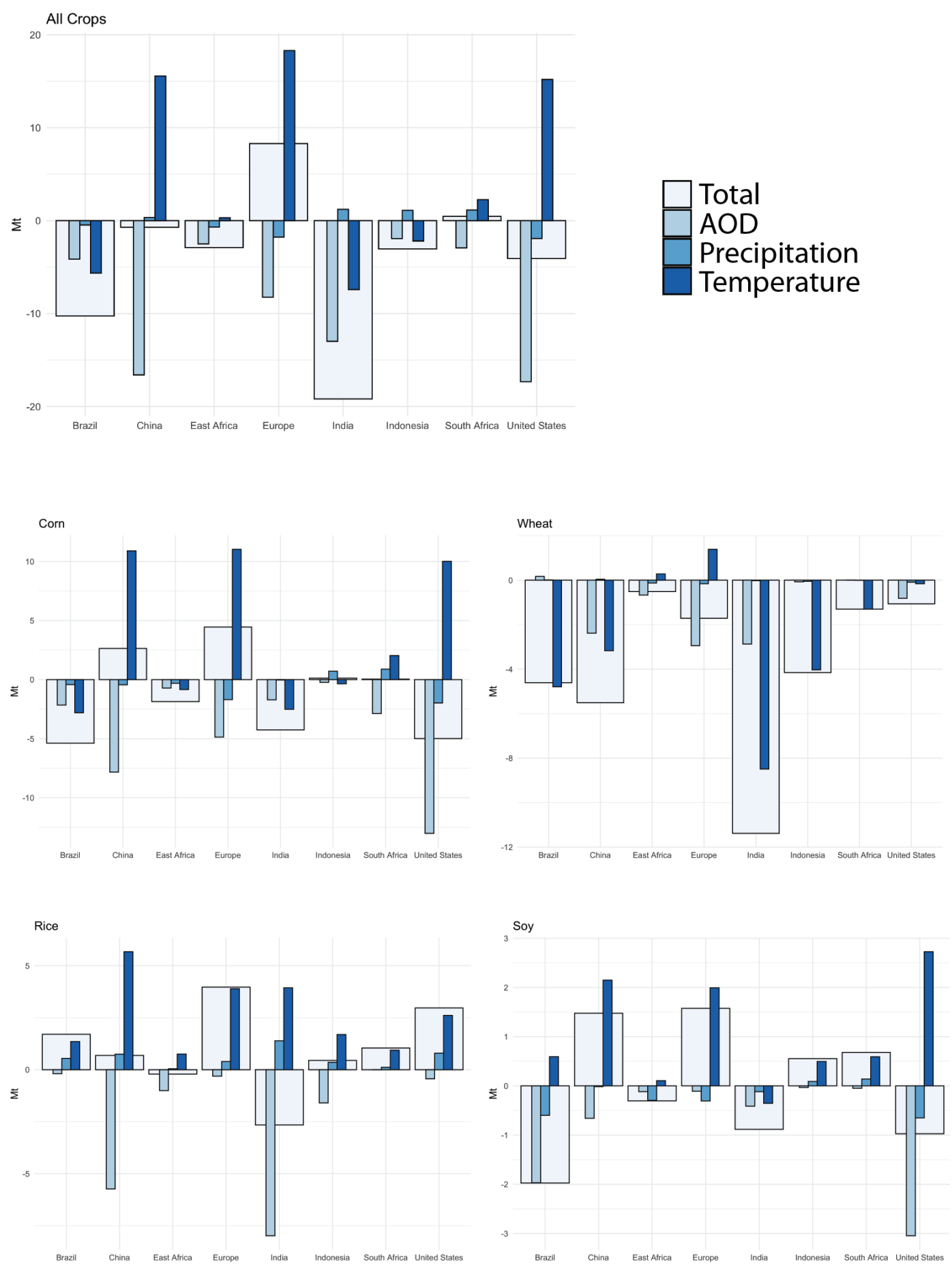

Fig. S6. The contribution of AOD, temperature, and precipitation effects due to aerosol emissions from each of the eight source regions to the total changes in productivity for the four staple crops (corn, wheat, soy, and rice) and their total (all crops) shows the sometimes-aligned, sometimes-canceling effects of crop responses to different physical system changes. Light (total) bars match total impacts reported in Table S11. 
(A) Global Partitioning of Infant Mortality Impacts

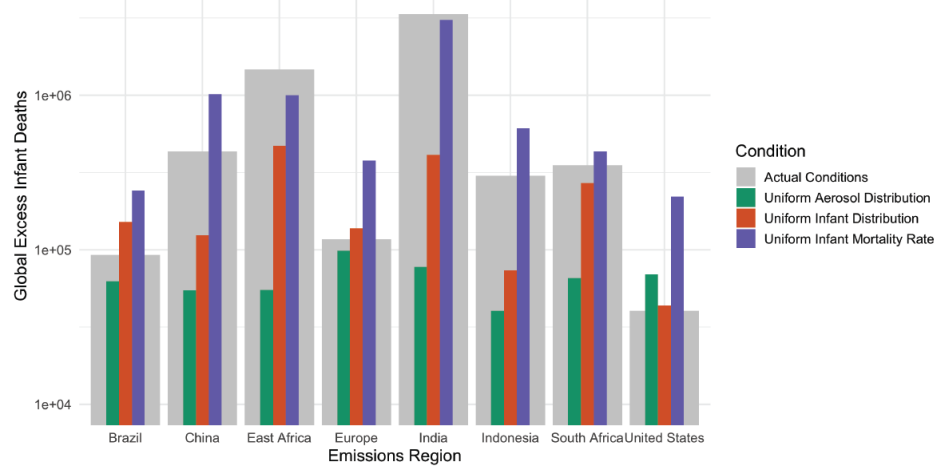

(C) Global Partitioning of Crop Production Impacts

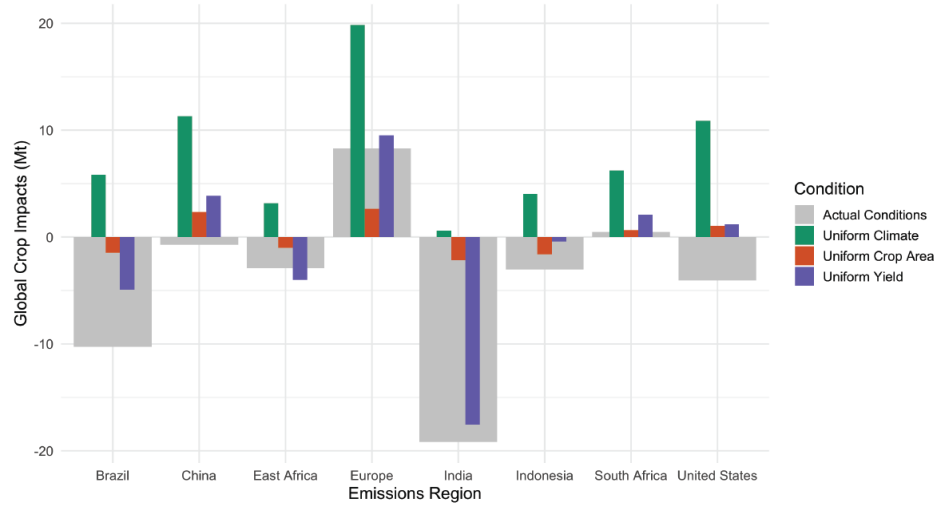

(E) Global Partitioning of Economic Impacts

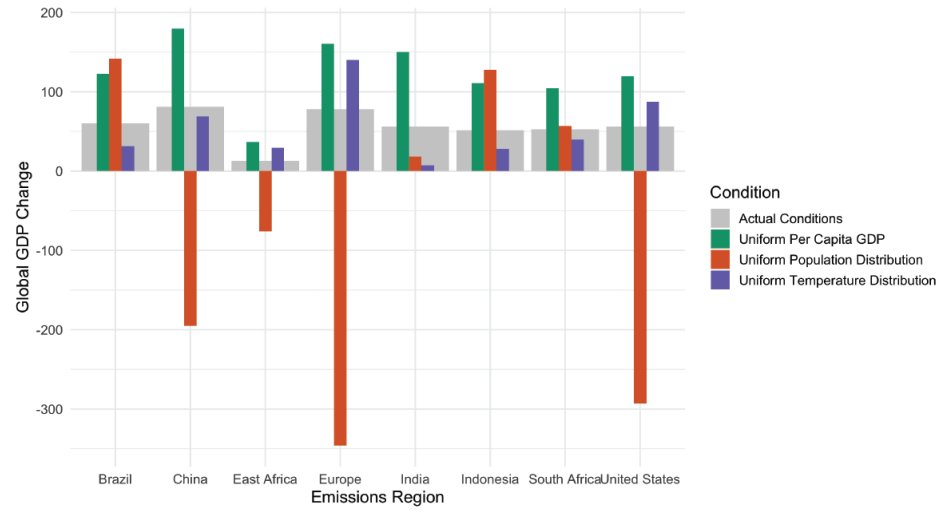

(B) Country-Level Infant Mortality Impacts

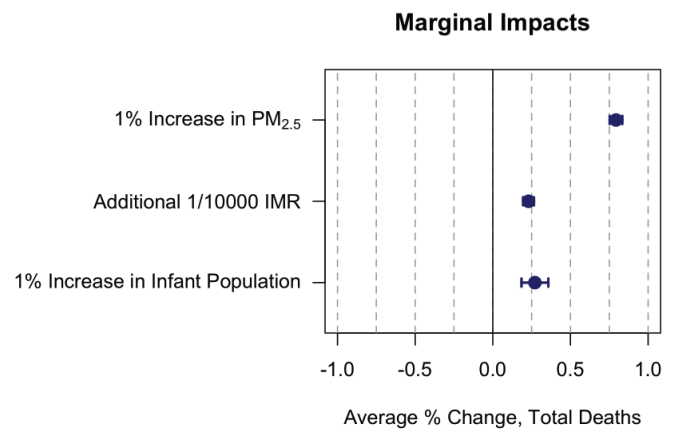

(D) Country-Level Crop Production Impacts

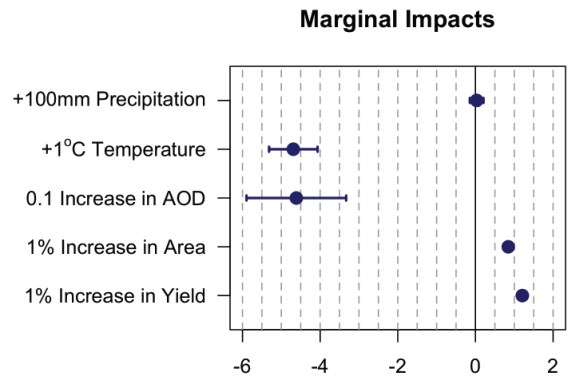

Average \% Change, Crop Production

\section{(F) Country-Level Economic Impacts}

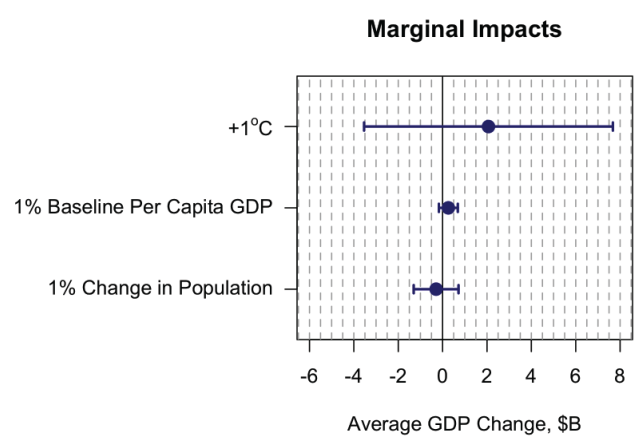

Fig. S7. Left-hand column shows the contribution of the spatial pattern of human systems (orange), baseline vulnerability (purple), and physical system changes due to aerosol emissions (green) to the total global impacts estimated from each emission region (grey). Where colored bars are smaller than the total, the actual spatial distribution of that factor (e.g. crop yield) magnifies the impact relative to a uniform baseline. Grey bars in top row match total impacts reported in Tables S10, S11, and S12. Right-hand column shows the country-level associations between total impacts and human system distribution, vulnerability, and physical system impacts across the true experimental conditions and the three comparison scenarios. 

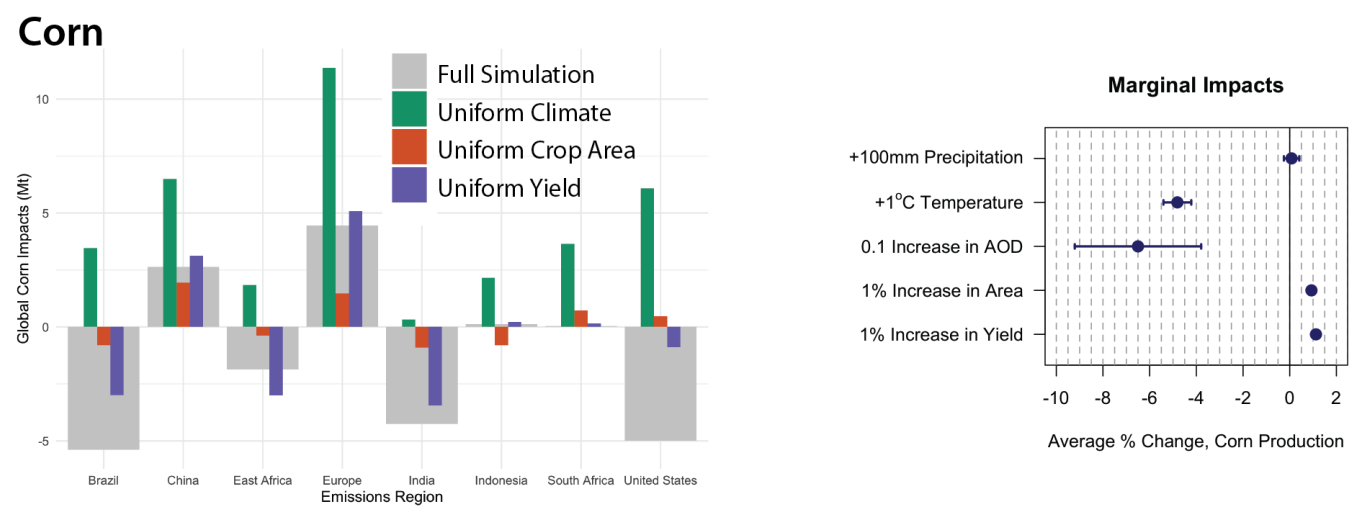

\section{Wheat}
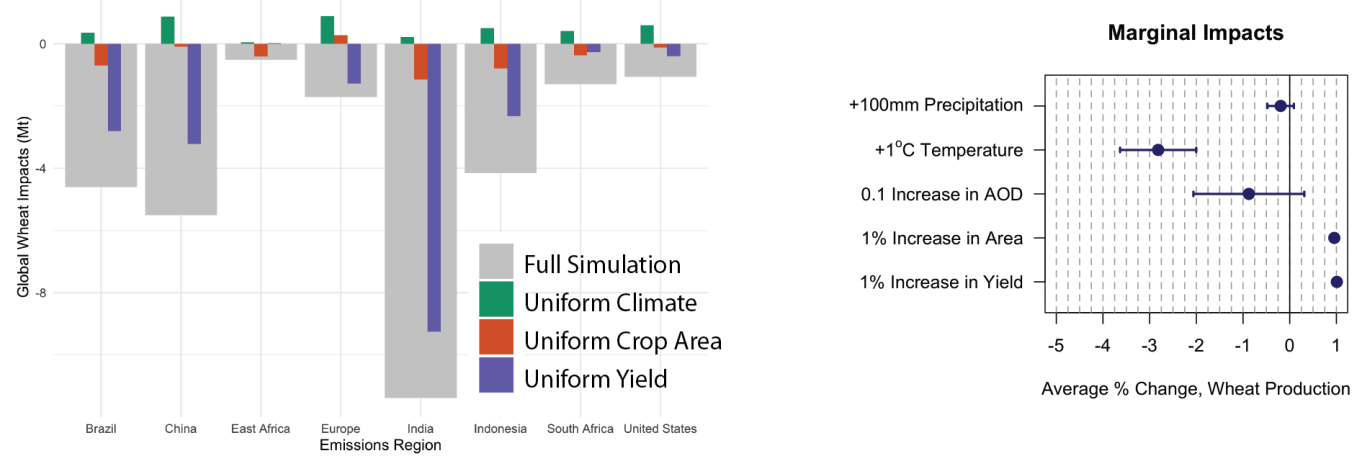

Average \% Change, Wheat Production
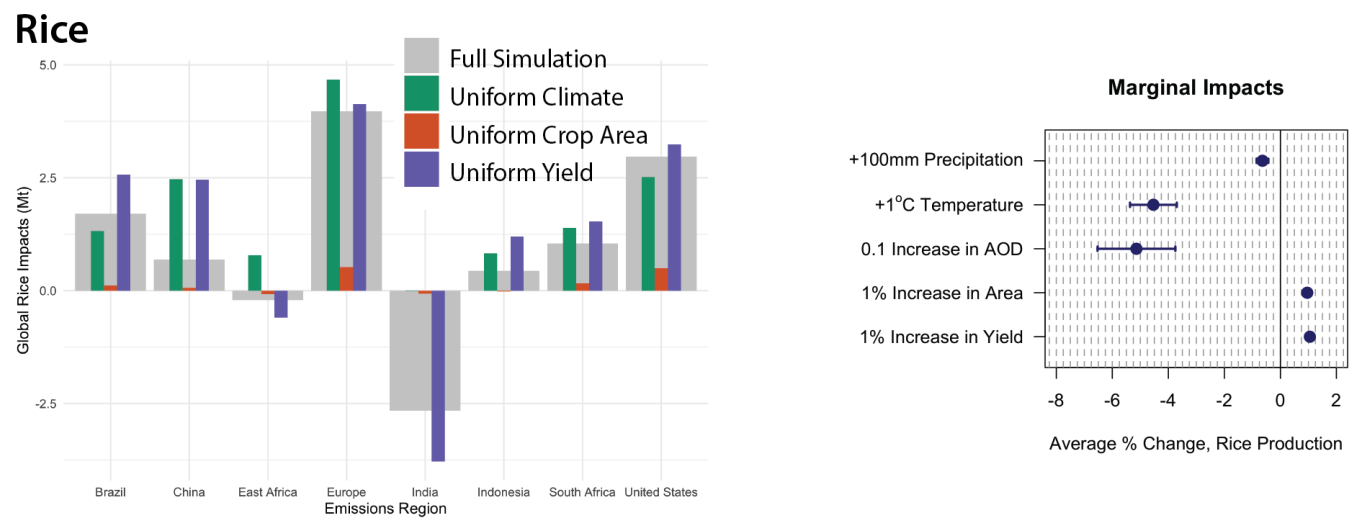

\section{Soybeans}
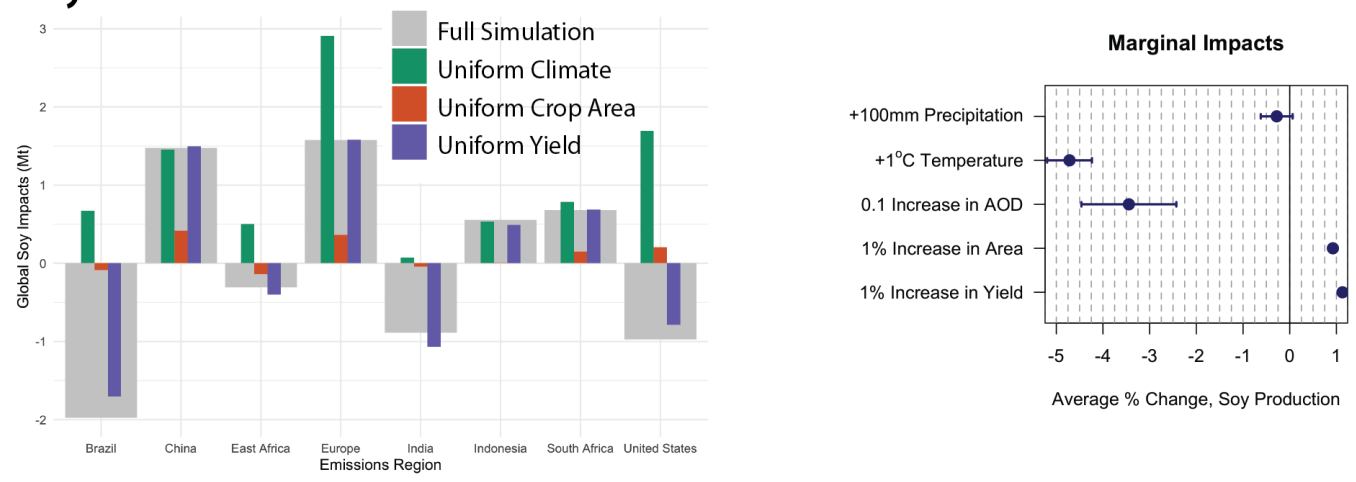

Fig. S8. As in Figure S7, but showing individual staple crops. 
(A) Infant Mortality

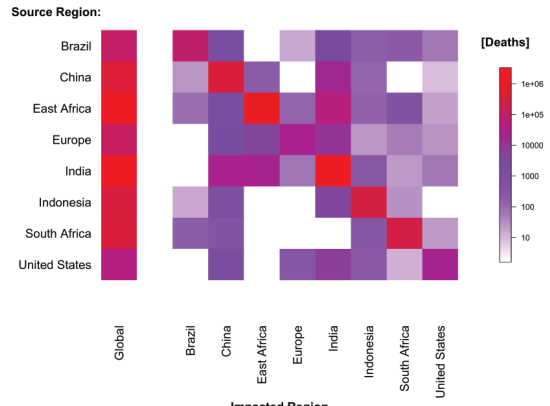

(B) Crop Production

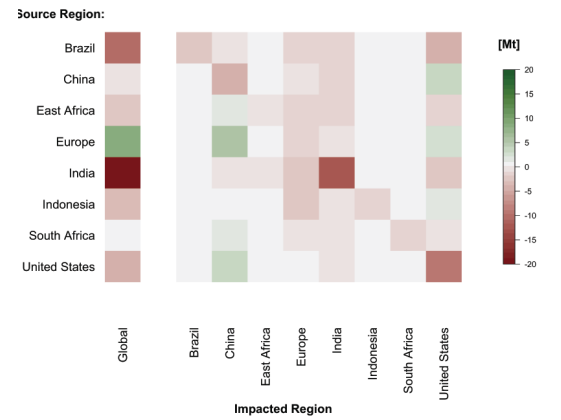

(C) Gross Domestic Product

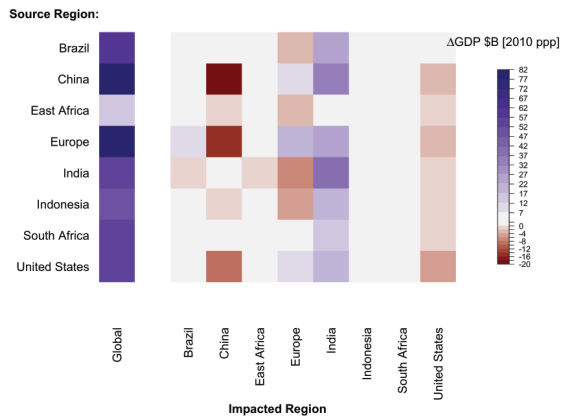

Fig. S9. Total global and pairwise 'source-receptor' relationships for (A) infant mortality, (b) crop production, and (c) economic output among the 8 emissions source regions vary widely. Most teleconnections are uni-directional (e.g., East Africa affects India, but not the other way around; India affects China but not the other way around). 


\section{(A) AOD-Only}

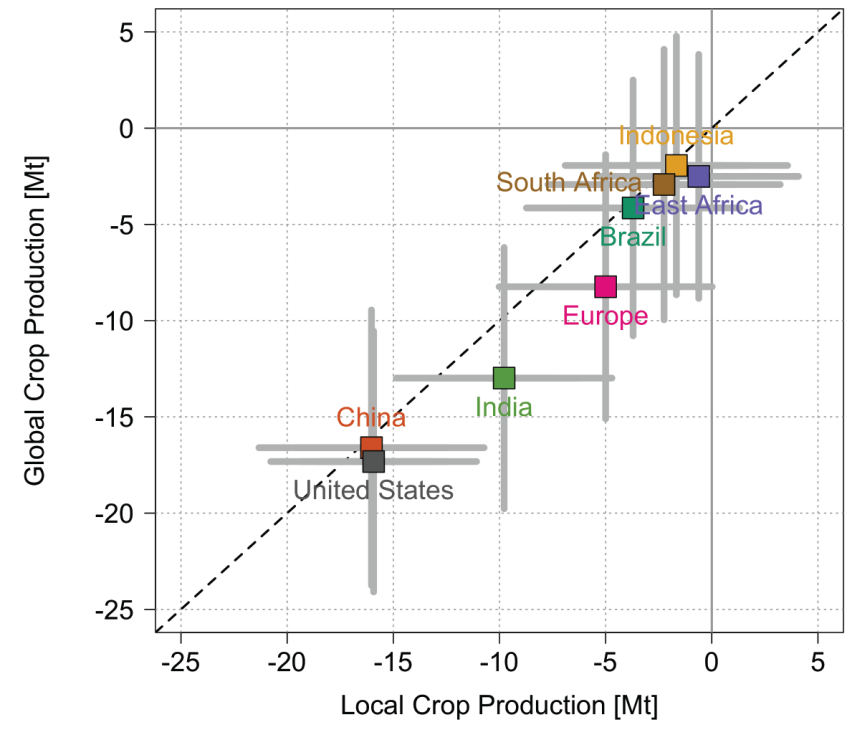

\section{(B) Self-Consistent AOD, T, P}

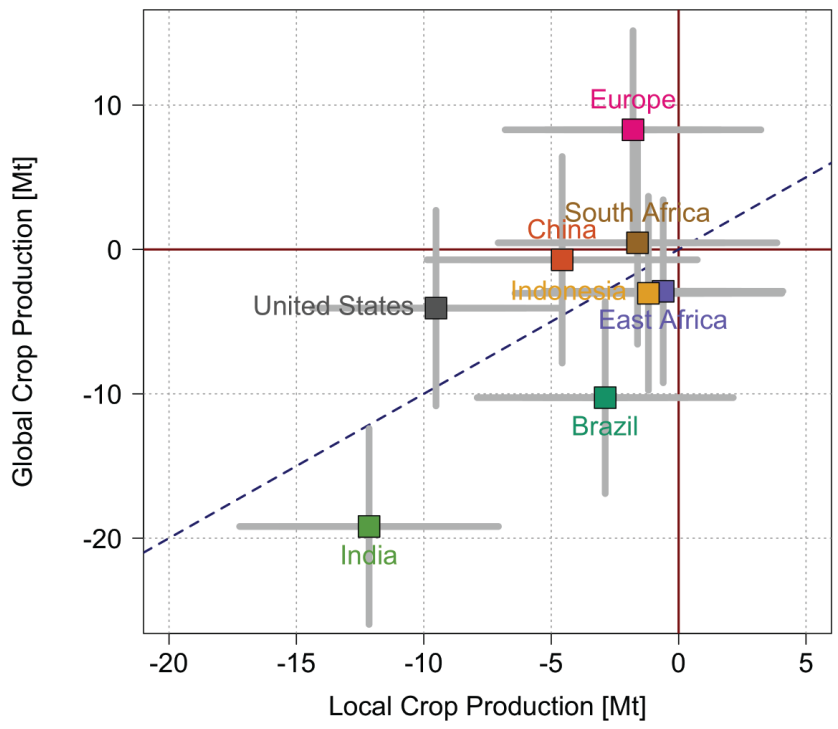

Fig. S10. Estimated crop production impacts when (A) only a partial impact (AOD) is used, versus (B) when the full suite of environmental changes (Temperature, Precipitation, and $A O D$ ) is used to calculate impacts in a multi-dimensional exposure-response function. The single-variable version results in mis-estimated impacts by including only a partial response: it estimates uniformly negative impacts from reduced incoming solar radiation, but neglects partially-offsetting positive impacts, including reduced heat exposure. For clarity, only climate-related uncertainty (grey bars) is shown. 


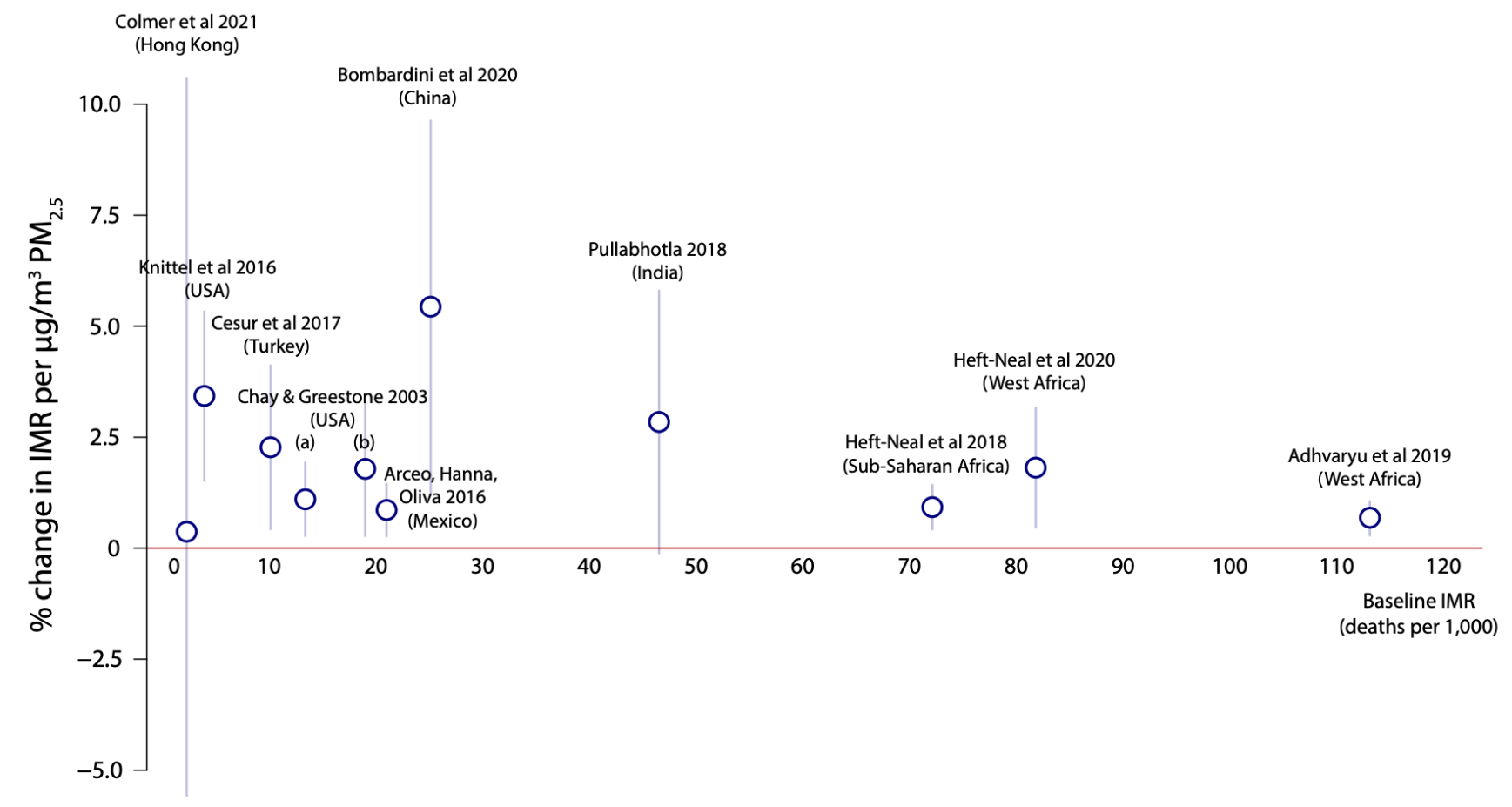

Fig. S11. Quasi-experimental estimates of the percentage change in infant mortality per unit of $\mathrm{PM}_{2.5}$ exposure show relative stability across the distribution of infant mortality. Estimate drawn from Heft-Neal et. al. 2018(1) is similar or conservative relative to other available estimates.(2-11) 


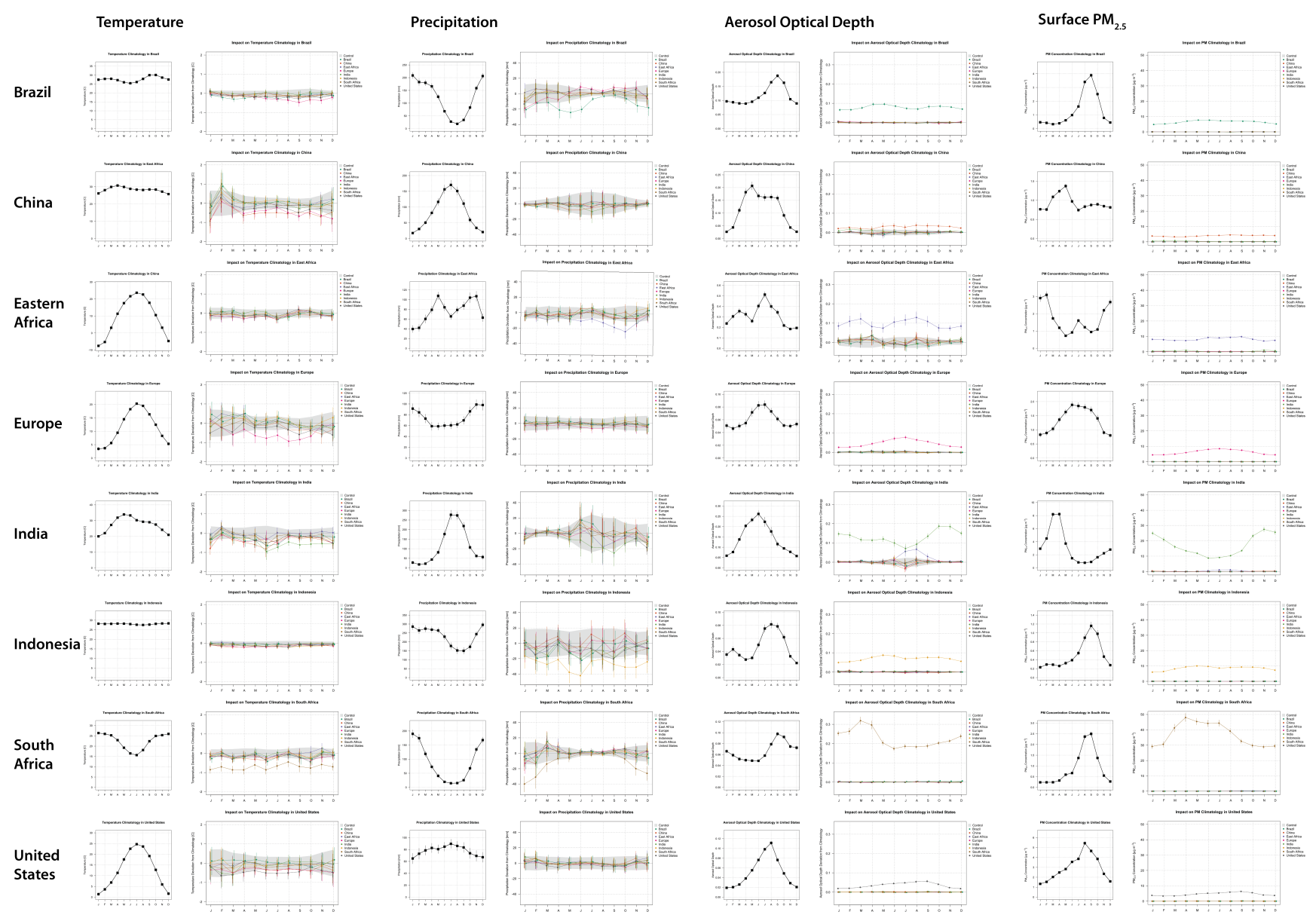

Fig. S12. The seasonality of physical system changes has important implications for human impacts. As a simple model, we show here the connections between the 8 experimental regions. Four pairs of plots are shown for each region, for temperature, precipitation, column AOD, and surface PM 2.5 . Each region's climatology for the control scenario is the left plot of the pair, with the climatology of impacts from each experiment shown in deviations in the right plot of each pair. The grey region in the impact plot shows the $95 \%$ confidence interval for natural variability in that month's value. For example, Europe's baseline temperature is unimodal, peaking in boreal summer. Aerosol emissions from Europe (pink line) reduce temperature most strongly in the summer months, but US emissions also reduce European temperatures relative to baseline in late summer. The seasonal variability in impacts is important for agricultural impacts, due to interactions with growing seasons, as well as for any impact based on shorter-run (< annual) variations. In particular, infants may be most sensitive to air quality during their first month of life, so Indian aerosol emissions would affect local infants most strongly in Oct-Nov-Dec, but emissions from Eastern Africa would also contribute to Indian impacts in July and August. 


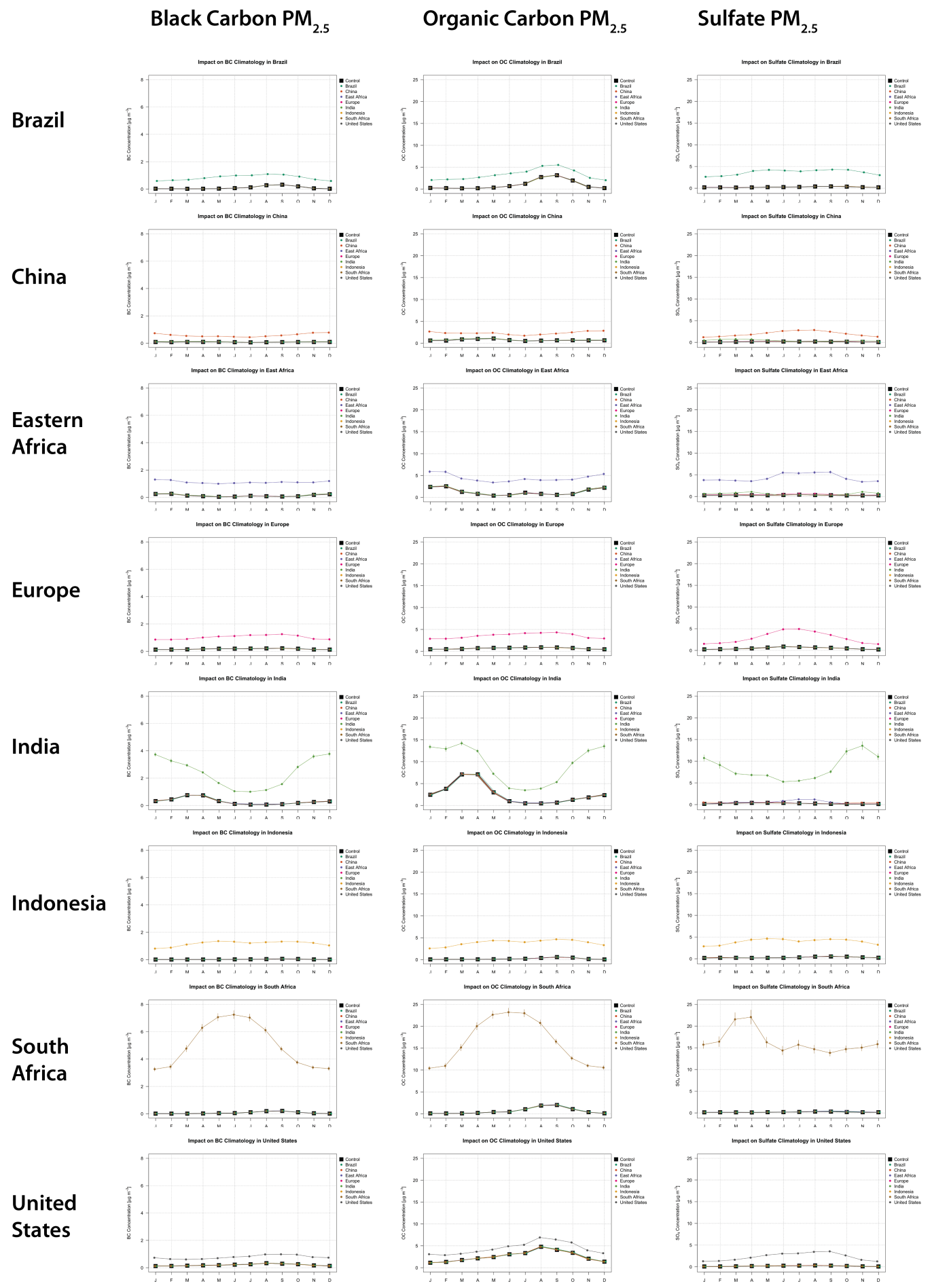

Fig. S13. Different chemistry (e.g., sulfate formation from sulfur dioxide), aging, and deposition mechanisms result in different chemical composition of surface PM 2.5 during the year across regions, even in our experimental conditions of uniform emissions throughout the year. For example, carbonaceous aerosols (BC+OC) dominate the mix in the United States throughout the year, with overall concentrations peaking in August-September. In South Africa, however, the main component is carbonaceous aerosols in the July-August, but sulfates in December-January. At present most empirical damage functions consider all $\mathrm{PM}_{2.5}$ jointly, but research suggests that different chemical species are likely to vary in toxicity. 

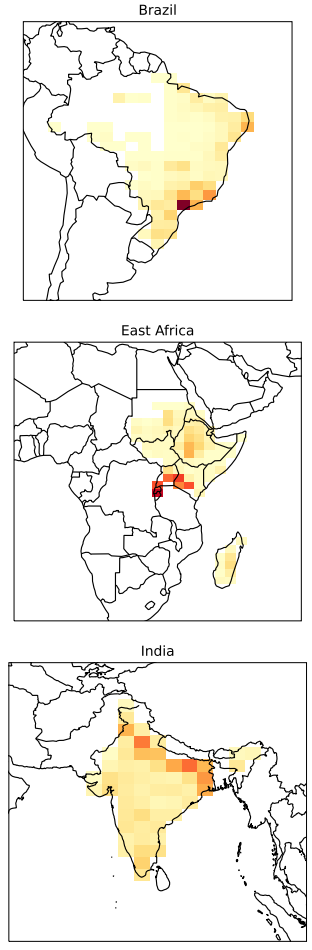

South Africa

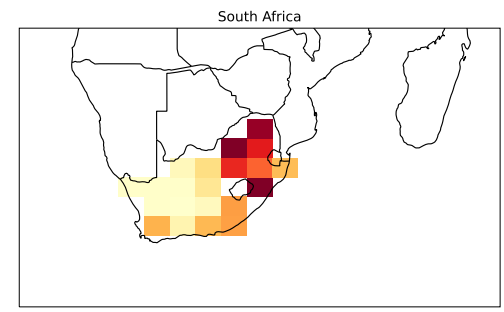

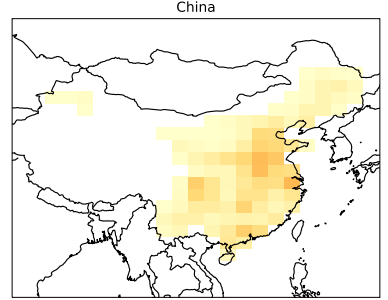

Europe

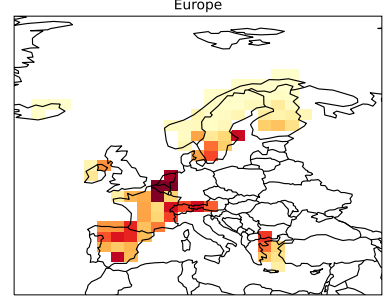

Indonesia
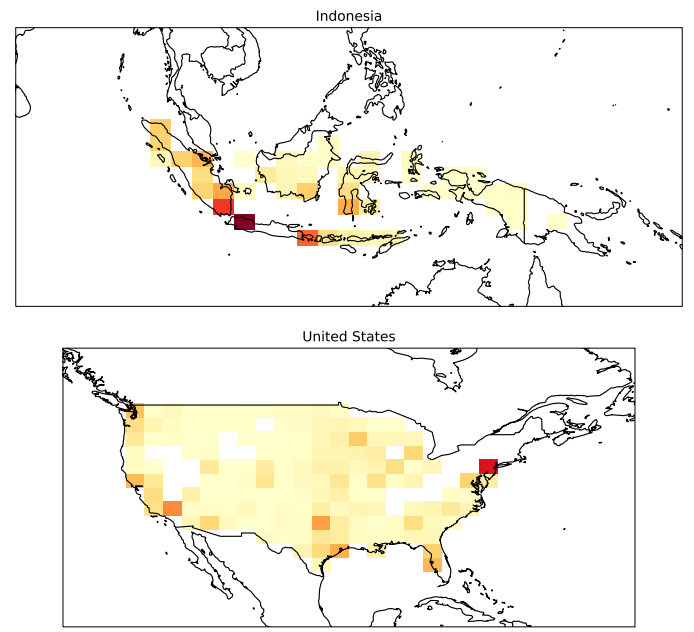

Fig. S14. The spatial distribution of net $\mathrm{BC}, \mathrm{OC}$, and $\mathrm{SO}_{2}$ surface emissions imposed within each of the 8 regional perturbation experiments is shown. Each grid cell is shaded according to the percent of the total regional emission originating from that grid cell in the perturbation experiment. Emissions are distributed according to the realistic year 2000 spatial distribution of emissions from Lamarque et al. (12) 


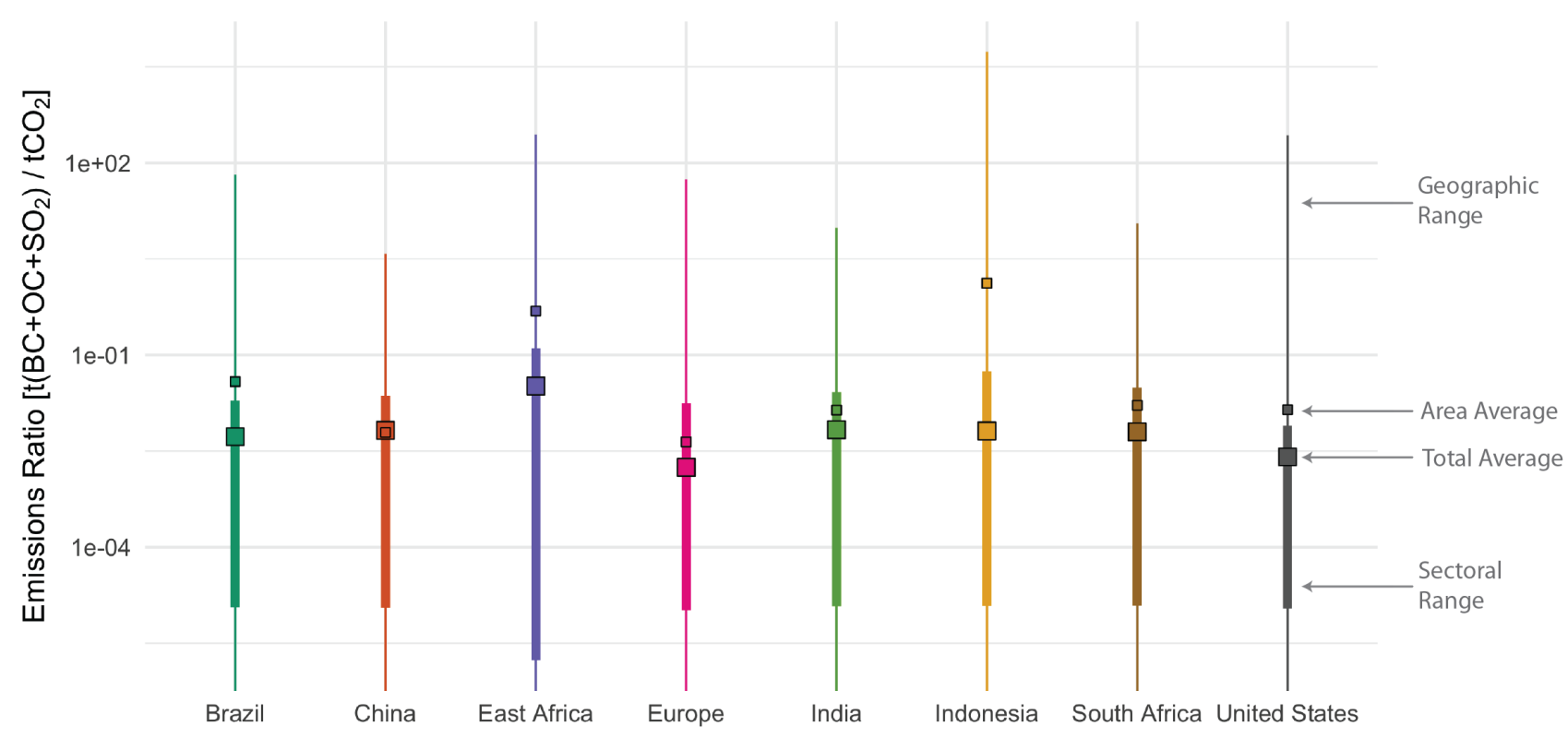

Fig. S15. The ratio of aerosols-to- $\mathrm{CO}_{2}$ emissions varies within the experiment source regions, both geographically and by sector. Lines show the range of ratio values over source region area, by half-degree grid cell (thin line), and by sector (thick line). Small squares show the areal averages of grid-cell-level ratios, and large squares show the average co-emissions ratio based on regional totals (the central estimate used in the analyses presented in the main manuscript). Data are from the EDGAR emissions inventory. (13) 


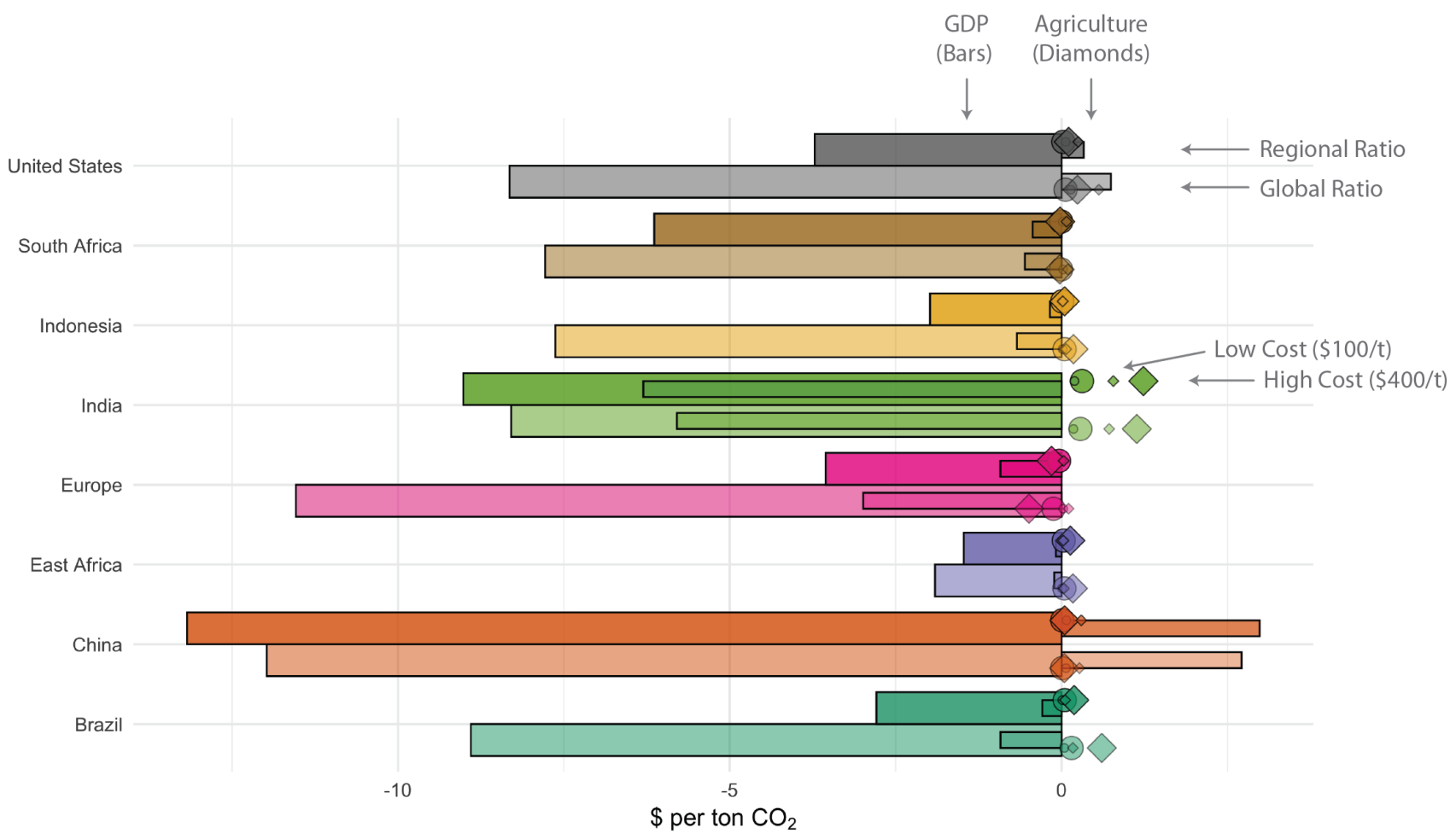

Fig. S16. Comparison between crop production and GDP impacts of aerosols, calculated in a number of ways. Crop production is the sum of wheat, rice, corn, and soybeans Because agricultural damages or benefits from aerosol emissions might be captured by overall GDP effects, we report only GDP+mortality costs in Figure 3. As in the main manuscript, wide bars and large points show global total impacts; thinner bars and smaller points show local impacts (local to the emitting region). Social costs are calculated for two different aerosol-to- $\mathrm{CO}_{2}$ ratios (for each region, the lower set $=$ global average ratio and the upper set = regional average ratio) and low and high crop prices $(\$ 100 /$ tonne and $\$ 400 /$ tonne; circles and diamonds, respectively). Note that negative costs reflect increases in GDP, largely driven by temperature effects in hotter locations. 
Table S1. Summary of global average physical impacts for each emissions region.

\begin{tabular}{lcccc}
\hline \hline Country & $\mathrm{PM}_{2.5}\left[\mu \mathrm{g} \mathrm{m}^{-3}\right]$ & $\mathrm{AOD}$ & $\mathrm{T}\left[{ }^{\circ} \mathrm{C}\right]$ & $\mathrm{P}[\mathrm{mm}]$ \\
\hline Brazil & $0.110( \pm 0.006)$ & $0.001( \pm 0.001)$ & $-0.083( \pm 0.140)$ & $-4.700( \pm 3.600)$ \\
China & $0.097( \pm 0.007)$ & $0.001( \pm 0.001)$ & $-0.180( \pm 0.140)$ & $-6.200( \pm 3.600)$ \\
East Africa & $0.097( \pm 0.007)$ & $0.002( \pm 0.001)$ & $-0.078( \pm 0.120)$ & $-3.900( \pm 3.600)$ \\
Europe & $0.170( \pm 0.011)$ & $0.002( \pm 0.001)$ & $-0.370( \pm 0.130)$ & $-10( \pm 2.900)$ \\
India & $0.140( \pm 0.007)$ & $0.001( \pm 0.001)$ & $-0.019( \pm 0.140)$ & $-1.700( \pm 3.300)$ \\
Indonesia & $0.071( \pm 0.007)$ & $0.001( \pm 0.001)$ & $-0.074( \pm 0.130)$ & $-4.600( \pm 2.900)$ \\
South Africa & $0.120( \pm 0.009)$ & $0.001( \pm 0.001)$ & $-0.110( \pm 0.120)$ & $-6.200( \pm 3.700)$ \\
United States & $0.120( \pm 0.008)$ & $0.002( \pm 0.001)$ & $-0.230( \pm 0.120)$ & $-6.900( \pm 2.800)$ \\
\hline
\end{tabular}


Table S2. Infant Mortality Rate Damage Function.(1) The dependent variable is a local infant mortality rate (deaths in the first year of life per $100 \mathrm{k}$ births). $\mathbf{P M}_{2.5}$ is in $\mu \mathrm{g} \mathrm{m} \mathrm{m}^{-3}$ averaged over the first year of life of the infant. Standard errors shown in parentheses.

\begin{tabular}{cc}
\hline \hline & $\log ($ InfantMortalityRate $)$ \\
\hline$P M_{2.5}$ & 0.09 \\
& $(0.026)$ \\
\hline
\end{tabular}

Table S3. Crop Damage Functions.(14) Parameter estimates for the influence of SAOD, Temperature and Precipitation on corn, wheat, soy and rice yields. Standard errors shown in parentheses. Response functions are plotted in Extended Data Fig. 2 of Ref. Proctor et al. 2018.

\begin{tabular}{lcccc}
\hline \hline & $\log \left(\right.$ Yield $\left._{\text {corn }}\right)$ & $\log ($ Yield wheat $)$ & $\log \left(\right.$ Yield $\left._{\text {soy }}\right)$ & $\log \left(\right.$ Yield $\left._{\text {rice }}\right)$ \\
\hline SAOD & -0.649 & -0.257 & -0.482 & -0.301 \\
& $(1.122 \mathrm{e}-01)$ & $(1.205 \mathrm{e}-01)$ & $(2.701 \mathrm{e}-01)$ & $(2.173 \mathrm{e}-01)$ \\
Temp. (RCS feature 1) & 0.197 & 0.0678 & 0.129 & .00266 \\
& $(7.184 \mathrm{e}-02)$ & $(2.363 \mathrm{e}-02)$ & $(8.058 \mathrm{e}-02)$ & $(4.703 \mathrm{e}-02)$ \\
Temp. (RCS feature 2) & -.000321 & -.000183 & -.000244 & .0000163 \\
& $(1.082 \mathrm{e}-04)$ & $(4.290 \mathrm{e}-05)$ & $(1.136 \mathrm{e}-04)$ & $(6.213 \mathrm{e}-05)$ \\
Temp. (RCS feature 3) & .00104 & .000816 & .000804 & -.000157 \\
& $(3.886 \mathrm{e}-04)$ & $(2.315 \mathrm{e}-04)$ & $(4.074 \mathrm{e}-04)$ & $(2.304 \mathrm{e}-04)$ \\
Precip. (RCS feature 1) & .00274 & .000186 & .00323 & -.00115 \\
& $(8.0623 \mathrm{e}-04)$ & $(9.623 \mathrm{e}-04)$ & $(1.575 \mathrm{e}-03)$ & $(6.285 \mathrm{e}-04)$ \\
Precip. (RCS feature 2) & $-4.09 \mathrm{e}-08$ & $-3.05 \mathrm{e}-09$ & $-4.97 \mathrm{e}-08$ & $1.34 \mathrm{e}-08$ \\
& $(1.175 \mathrm{e}-08)$ & $(2.007 \mathrm{e}-08)$ & $(2.452 \mathrm{e}-08)$ & $(9.839 \mathrm{e}-09)$ \\
& & & & \\
\hline
\end{tabular}

Table S4. Economic Damage Function.(15) The dependent variable is per capita GDP growth rate. $T$ is in degrees Celsius averaged over a calendar year. Standard errors shown in parentheses.

\begin{tabular}{lc}
\hline \hline & $\Delta\left(G D P_{\text {per capita }}\right)$ \\
\hline$T_{\text {avg }}$ & 0.01268 \\
& $(0.003248)$ \\
$T_{\text {avg }}^{2}$ & -0.0004942 \\
& $(0.0001024)$ \\
\hline
\end{tabular}

Table S5. Total impacts for identical total $\mathrm{BC}+\mathrm{OC}+\mathrm{SO}_{2}$ emissions from each of the 8 source regions. Excess infant ( $\left.<1 \mathrm{y}\right)$ deaths, total crop production changes, and economic productivity changes are shown with both global totals and the portion confined to the emissions source region.

\begin{tabular}{lcccccc}
\hline \hline & \multicolumn{2}{c}{$\begin{array}{c}\text { Infant Mortality } \\
\text { [Excess Deaths] }\end{array}$} & \multicolumn{2}{c}{ Crop Production } & \multicolumn{2}{c}{ GDP } \\
& Global & Local & Global & Local & Global & Local \\
\hline Brazil & 92,584 & 78,445 & -10.3 & -2.9 & 61.5 & 6.2 \\
China & 432,705 & 387,068 & -0.7 & -4.6 & 85.4 & -16.6 \\
East Africa & $1,468,102$ & $1,253,009$ & -2.9 & -0.6 & 13.4 & 0.8 \\
Europe & 116,773 & 23,002 & 8.3 & -1.8 & 85.8 & 22.5 \\
India & $3,342,144$ & $3,077,521$ & -19.2 & -12.1 & 57.1 & 40 \\
Indonesia & 301,818 & 283,114 & -3 & -1.2 & 52.3 & 4.6 \\
South Africa & 353,397 & 261,443 & 0.5 & -1.6 & 52.5 & 3.9 \\
United States & 40,390 & 20,757 & -4.1 & -9.5 & 59.2 & -3.5 \\
\hline
\end{tabular}


Table S6. Total impacts for each of the 8 emitting regions per Tg of emitted aerosol. Excess infant $(<1 \mathrm{y})$ deaths, total crop production changes, and economic productivity changes are shown with both global totals and the portion confined to the emissions source region.

\begin{tabular}{lcccccc}
\hline \hline & \multicolumn{2}{c}{$\begin{array}{c}\text { Infant Mortality } \\
\text { [Excess Deaths] }\end{array}$} & \multicolumn{2}{c}{$\begin{array}{c}\text { Crop Production } \\
\text { [Mt Crops] }\end{array}$} & \multicolumn{2}{c}{ GDP } \\
& Global 2010)] & Local & Global & Local & Global & Local \\
\hline Brazil & $3,301.9$ & $2,797.6$ & -0.4 & -0.1 & 2.1 & 0.2 \\
China & $15,431.7$ & $13,804.1$ & 0 & -0.2 & 2.9 & -0.7 \\
East Africa & $52,357.4$ & $44,686.5$ & -0.1 & 0 & 0.5 & 0 \\
Europe & $4,164.5$ & 820.3 & 0.3 & -0.1 & 2.8 & 0.7 \\
India & 119,192 & $109,754.7$ & -0.7 & -0.4 & 2 & 1.4 \\
Indonesia & $10,763.8$ & $10,096.8$ & -0.1 & 0 & 1.8 & 0.2 \\
South Africa & $12,603.3$ & $9,323.9$ & 0 & -0.1 & 1.9 & 0.1 \\
United States & $1,440.4$ & 740.3 & -0.1 & -0.3 & 2 & -0.2 \\
\hline
\end{tabular}


Table S7. The top panel of the table shows aerosol impacts normalized to the full emissions basket, or the impacts per ton of $\mathrm{CO}_{2}$ emitted, due to the impacts of the co-emitted aerosols, calculated using global average ratios of aerosols to $\mathrm{CO}_{2}$. Both global totals and impacts confined to the emissions source region (local) are shown. The bottom panel provides monetary values for normalized per- $\mathrm{CO}_{2}$ impact values, converted using VSL values from Viscusi et. al.(16) and a per-ton crop price of $\$ 300$. In the bottom panel, negative signs correspond to losses, positive to gains.

\begin{tabular}{|c|c|c|c|c|c|c|}
\hline & \multicolumn{2}{|c|}{ Infant Mortality } & \multicolumn{2}{|c|}{ Crop Production } & \multicolumn{2}{|c|}{ GDP } \\
\hline & Global & Local & Global & Local & Global & Local \\
\hline & $\#$ per $\mathrm{tCO}_{2}$ & \# per $\mathrm{tCO}_{2}$ & $\mathrm{t}$ per $\mathrm{tCO}_{2}$ & $\mathrm{t}$ per $\mathrm{tCO}_{2}$ & $\$$ per $\mathrm{tCO}_{2}$ & $\$$ per $\mathrm{tCO}_{2}$ \\
\hline Brazil & 0.00001 & 0.00001 & -0.002 & -0.0004 & 8.90 & 0.92 \\
\hline China & 0.0001 & 0.0001 & -0.0001 & -0.001 & 12 & -2.70 \\
\hline East Africa & 0.0002 & 0.0002 & -0.0004 & -0.0001 & 1.90 & 0.11 \\
\hline Europe & 0.00002 & 0.00000 & 0.001 & -0.0003 & 12 & 3 \\
\hline India & 0.0005 & 0.0004 & -0.003 & -0.002 & 8.30 & 5.80 \\
\hline Indonesia & 0.00004 & 0.00004 & -0.0004 & -0.0002 & 7.60 & 0.67 \\
\hline South Africa & 0.0001 & 0.00004 & 0.0001 & -0.0002 & 7.80 & 0.55 \\
\hline \multirow[t]{2}{*}{ United States } & 0.00001 & 0.00000 & -0.001 & -0.001 & 8.30 & -0.74 \\
\hline & $\$$ per $\mathrm{tCO}_{2}$ & $\$$ per $\mathrm{tCO}_{2}$ & $\$$ per $\mathrm{tCO}_{2}$ & $\$$ per $\mathrm{tCO}_{2}$ & $\$$ per $\mathrm{tCO}_{2}$ & $\$$ per $\mathrm{tCO}_{2}$ \\
\hline Brazil & -23.26 & -19.71 & -0.46 & -0.13 & 8.90 & 0.92 \\
\hline China & -89.52 & -80.08 & -0.03 & -0.20 & 11.98 & -2.71 \\
\hline East Africa & -43.39 & -37.03 & -0.13 & -0.03 & 1.91 & 0.11 \\
\hline Europe & -51.77 & -10.20 & 0.37 & -0.08 & 11.54 & 2.99 \\
\hline India & -148.17 & -136.44 & -0.85 & -0.54 & 8.29 & 5.80 \\
\hline Indonesia & -13.38 & -12.55 & -0.13 & -0.05 & 7.63 & 0.67 \\
\hline South Africa & -52.23 & -38.64 & 0.02 & -0.07 & 7.78 & 0.55 \\
\hline United States & -57.30 & -29.45 & -0.18 & -0.42 & 8.32 & -0.74 \\
\hline
\end{tabular}


Table S8. As in Table S7, but with region-specific normalization based on emissions inventories.

\begin{tabular}{|c|c|c|c|c|c|c|}
\hline & \multicolumn{2}{|c|}{ Infant Mortality } & \multicolumn{2}{|c|}{ Crop Production } & \multicolumn{2}{|c|}{ GDP } \\
\hline & Global & Local & Global & Local & Global & Local \\
\hline & $\#$ per t $\mathrm{tCO}_{2}$ & $\#$ per $\mathrm{tCO}_{2}$ & $\mathrm{t}$ per $\mathrm{tCO}_{2}$ & $\mathrm{t}$ per $\mathrm{tCO}_{2}$ & $\$$ per $\mathrm{tCO}_{2}$ & $\$$ per $\mathrm{tCO}_{2}$ \\
\hline Brazil & 0.0000043 & 0.0000036 & -0.00048 & -0.00013 & 2.8 & 0.29 \\
\hline China & 0.00007 & 0.000063 & -0.00012 & -0.00074 & 13 & -3 \\
\hline East Africa & 0.00017 & 0.00014 & -0.00033 & -0.000069 & 1.5 & 0.086 \\
\hline Europe & 0.0000053 & 0.000001 & 0.00038 & -0.000081 & 3.6 & 0.92 \\
\hline India & 0.00054 & 0.00049 & -0.0031 & -0.002 & 9 & 6.3 \\
\hline Indonesia & 0.000012 & 0.000011 & -0.00012 & -0.000046 & 2 & 0.17 \\
\hline South Africa & 0.000041 & 0.00003 & 0.000054 & -0.00019 & 6.1 & 0.43 \\
\hline \multirow[t]{2}{*}{ United States } & 0.0000027 & 0.0000014 & -0.00027 & -0.00063 & 3.7 & -0.33 \\
\hline & $\$$ per $\mathrm{tCO}_{2}$ & $\$$ per $\mathrm{tCO}_{2}$ & $\$$ per $\mathrm{tCO}_{2}$ & $\$$ per $\mathrm{tCO}_{2}$ & $\$$ per $\mathrm{tCO}_{2}$ & $\$$ per $\mathrm{tCO}_{2}$ \\
\hline Brazil & -7.29 & -6.18 & -0.14 & -0.04 & 2.79 & 0.29 \\
\hline China & -98.49 & -88.1 & -0.03 & -0.22 & 13.18 & -2.99 \\
\hline East Africa & -33.51 & -28.6 & -0.1 & -0.02 & 1.47 & 0.09 \\
\hline Europe & -15.95 & -3.14 & 0.11 & -0.02 & 3.55 & 0.92 \\
\hline India & -161.1 & -148.34 & -0.92 & -0.59 & 9.02 & 6.3 \\
\hline Indonesia & -3.48 & -3.26 & -0.03 & -0.01 & 1.98 & 0.17 \\
\hline South Africa & -41.18 & -30.47 & 0.02 & -0.06 & 6.14 & 0.43 \\
\hline United States & -25.63 & -13.17 & -0.08 & -0.19 & 3.72 & -0.33 \\
\hline
\end{tabular}


Table S9. Comparison of aerosol social costs (infant mortality + GDP) calculated using three different VSLs (Viscusi et. al.(16), Harvard School of Public Health(17) + EPA(18) for US and Europe, and a global average VSL from Viscusi). Values correspond to the points plotted in Figure 3. All values are in USD, with positive indicating damages.

\begin{tabular}{lcccccc}
\hline \hline Region & $\begin{array}{c}\text { Viscusi } \\
\text { Global }\end{array}$ & $\begin{array}{c}\text { Viscusi } \\
\text { Local }\end{array}$ & $\begin{array}{c}\text { Average } \\
\text { Global }\end{array}$ & $\begin{array}{c}\text { Average } \\
\text { Local }\end{array}$ & $\begin{array}{c}\text { HSPH } \\
\text { Global }\end{array}$ & $\begin{array}{c}\text { HSPH } \\
\text { Local }\end{array}$ \\
\hline Brazil & 4.5 & 5.9 & 4.9 & 6.2 & 7.5 & 8.4 \\
China & 85.3 & 91.1 & 113.4 & 116.3 & 148.6 & 147.7 \\
East Africa & 32 & 28.5 & 300.1 & 257.3 & 65.6 & 57.1 \\
Europe & 12.4 & 2.2 & 6 & 1 & 47.5 & 9.1 \\
India & 152.1 & 142 & 957.6 & 883.8 & 528 & 488.2 \\
Indonesia & 1.5 & 3.1 & 18.9 & 19.4 & 17.7 & 18.3 \\
South Africa & 35 & 30 & 68 & 54.4 & 76.2 & 60.5 \\
United States & 21.9 & 13.5 & 1.1 & 2.8 & 21.9 & 13.5 \\
\hline
\end{tabular}




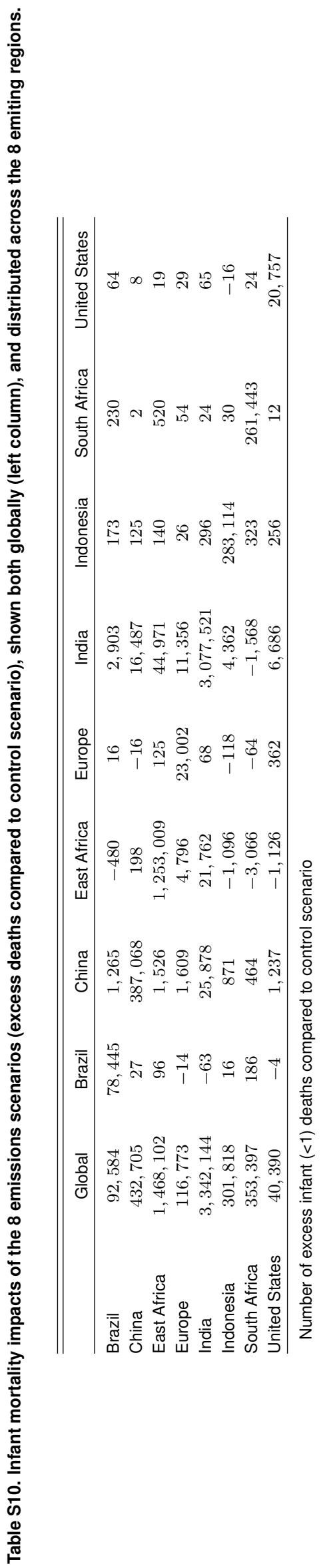




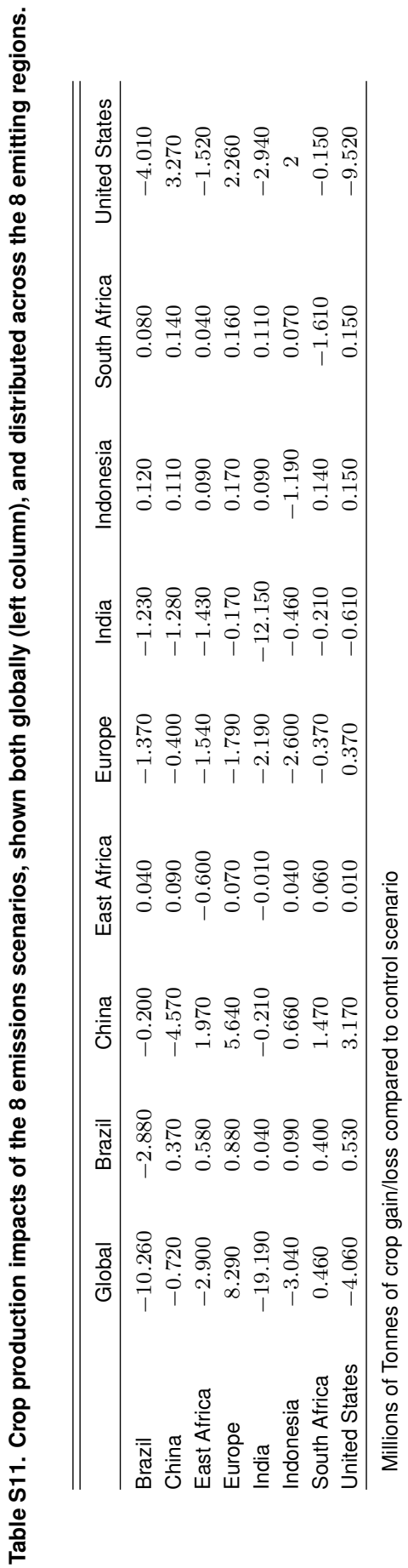




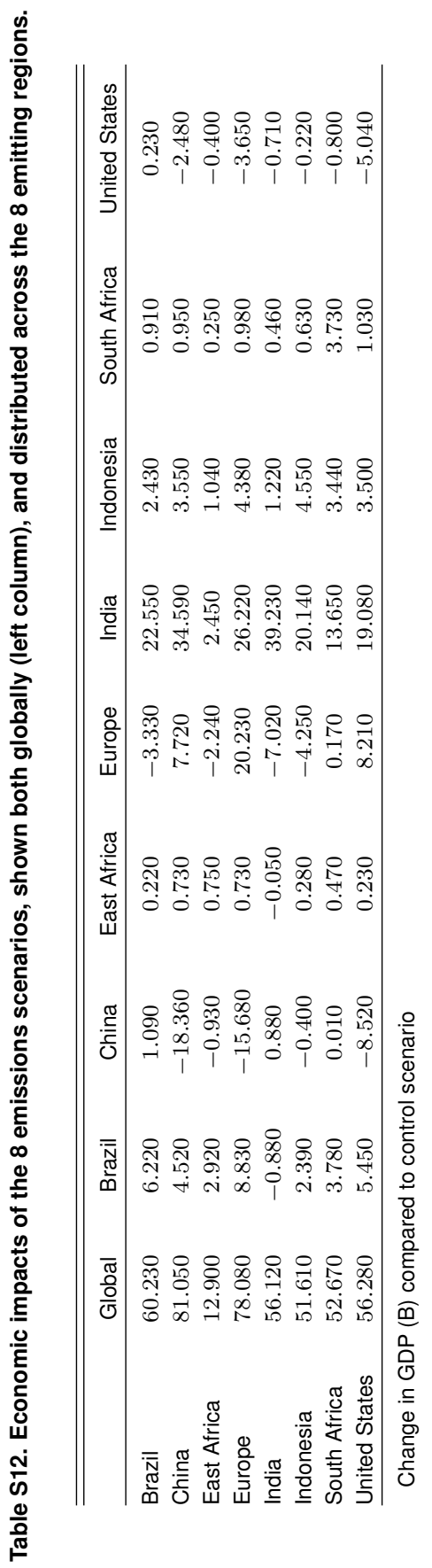




\section{References}

1. S Heft-Neal, J Burney, E Bendavid, M Burke, Robust relationship between air quality and infant mortality in africa. Nature 559, 254 (2018).

2. J Colmer, D Lin, S Liu, J Shimshack, Why are pollution damages lower in developed countries? insights from high-income, high-particulate matter hong kong. J. Heal. Econ. 79, 102511 (2021).

3. CR Knittel, DL Miller, NJ Sanders, Caution, drivers! children present: Traffic, pollution, and infant health. Rev. Econ. Stat. 98, 350-366 (2016).

4. R Cesur, E Tekin, A Ulker, Air pollution and infant mortality: evidence from the expansion of natural gas infrastructure. The Econ. J. 127, 330-362 (2017).

5. KY Chay, M Greenstone, The impact of air pollution on infant mortality: evidence from geographic variation in pollution shocks induced by a recession. The Q. J. Econ. 118, 1121-1167 (2003).

6. KY Chay, M Greenstone, Air quality, infant mortality, and the clean air act of 1970. Natl. Bureau Econ. Res. Work. Pap. No. 10053 (2003).

7. E Arceo, R Hanna, P Oliva, Does the effect of pollution on infant mortality differ between developing and developed countries? evidence from mexico city. The Econ. J. 126, 257-280 (2016).

8. M Bombardini, B Li, Trade, pollution and mortality in china. J. Int. Econ. 125, 103321 (2020).

9. H Pullabhotla, Fires, wind, and smoke: Air pollution and infant mortality. Work. Pap. (2018).

10. A Adhvaryu, et al., Dust and death: Evidence from the west african harmattan. The Econ. J. (forthcoming).

11. S Heft-Neal, J Burney, E Bendavid, KK Voss, M Burke, Dust pollution from the sahara and african infant mortality. Nat. Sustain. 3, 863-871 (2020).

12. JF Lamarque, et al., Historical (1850-2000) gridded anthropogenic and biomass burning emissions of reactive gases and aerosols: methodology and application. Atmos. Chem. Phys. 10, 7017-7039 (2010).

13. European Commission and Joint Research Centre (JRC) and Netherlands Environmental Assessment Agency (PBL), Emission Database for Global Atmospheric Research (EDGAR), release version 4.2 (2012).

14. J Proctor, S Hsiang, J Burney, M Burke, W Schlenker, Estimating global agricultural effects of geoengineering using volcanic eruptions. Nature p. 1 (2018).

15. M Burke, SM Hsiang, E Miguel, Global non-linear effect of temperature on economic production. Nature 527, 235 (2015).

16. WK Viscusi, CJ Masterman, Income elasticities and global values of a statistical life. J. Benefit-Cost Analysis 8, 226-250 (2017).

17. LA Robinson, JK Hammitt, L O'Keeffe, Valuing mortality risk reductions in global benefit-cost analysis. J. Benefit-Cost Analysis 10, 15-50 (2019).

18. United States Environmental Protection Agency (EPA), Mortality Risk Valuation (2019). 